\title{
BAMS
}

\section{The Northern Tornadoes Project}

\section{Uncovering Canada's True Tornado Climatology}

David M. L. Sills, Gregory A. Kopp, Lesley Elliott, Aaron L. Jaffe, Liz Sutherland, Connell S. Miller, Joanne M. Kunkel, Emilio Hong, Sarah A. Stevenson, and William Wang

\begin{abstract}
Canada is a vast country with most of its population located along its southern border. Large areas are sparsely populated and/or heavily forested, and severe weather reports are rare when thunderstorms occur there. Thus, it has been difficult to accurately assess the true tornado climatology and risk. It is also important to establish a reliable baseline for tornado-related climate change studies. The Northern Tornadoes Project (NTP), led by Western University, is an ambitious multidisciplinary initiative aimed at detecting and documenting every tornado that occurs across Canada. A team of meteorologists and wind engineers collects research-quality data during each damage investigation via thorough ground surveys and high-resolution satellite, aircraft, and drone imaging. Crowdsourcing through social media is also key to tracking down events. In addition, NTP conducts research to improve our ability to detect and accurately assess tornadoes that affect forests, cropland, and grassland. An open data website allows sharing of resulting datasets and analyses. Pilot investigations were carried out during the warm seasons of 2017 and 2018 , with the scope expanding from the detection of any tornadoes in heavily forested regions of central Canada in 2017 to the detection of all EF1+ tornadoes in Ontario plus all significant events outside of Ontario in 2018. The 2019 season was the first full campaign, systematically collecting research-quality tornado data across the entire country. To date, the project has found 89 tornadoes that otherwise would not have been identified, and increased the national tornado count in 2019 by $78 \%$.
\end{abstract}

https://doi.org/10.1175/BAMS-D-20-0012.1

Corresponding author: Dr. David M. L. Sills, david.sills@uwo.ca

In final form 17 August 2020

(02020 American Meteorological Society

For information regarding reuse of this content and general copyright information, consult the AMS Copyright Policy.

AfFILIATIONS: Sills, Kopp, Elliott, Jaffe, Sutherland, Miller, Kunkel, Hong, Stevenson, and Wang-Western Engineering, University of Western Ontario, London, Ontario, Canada 


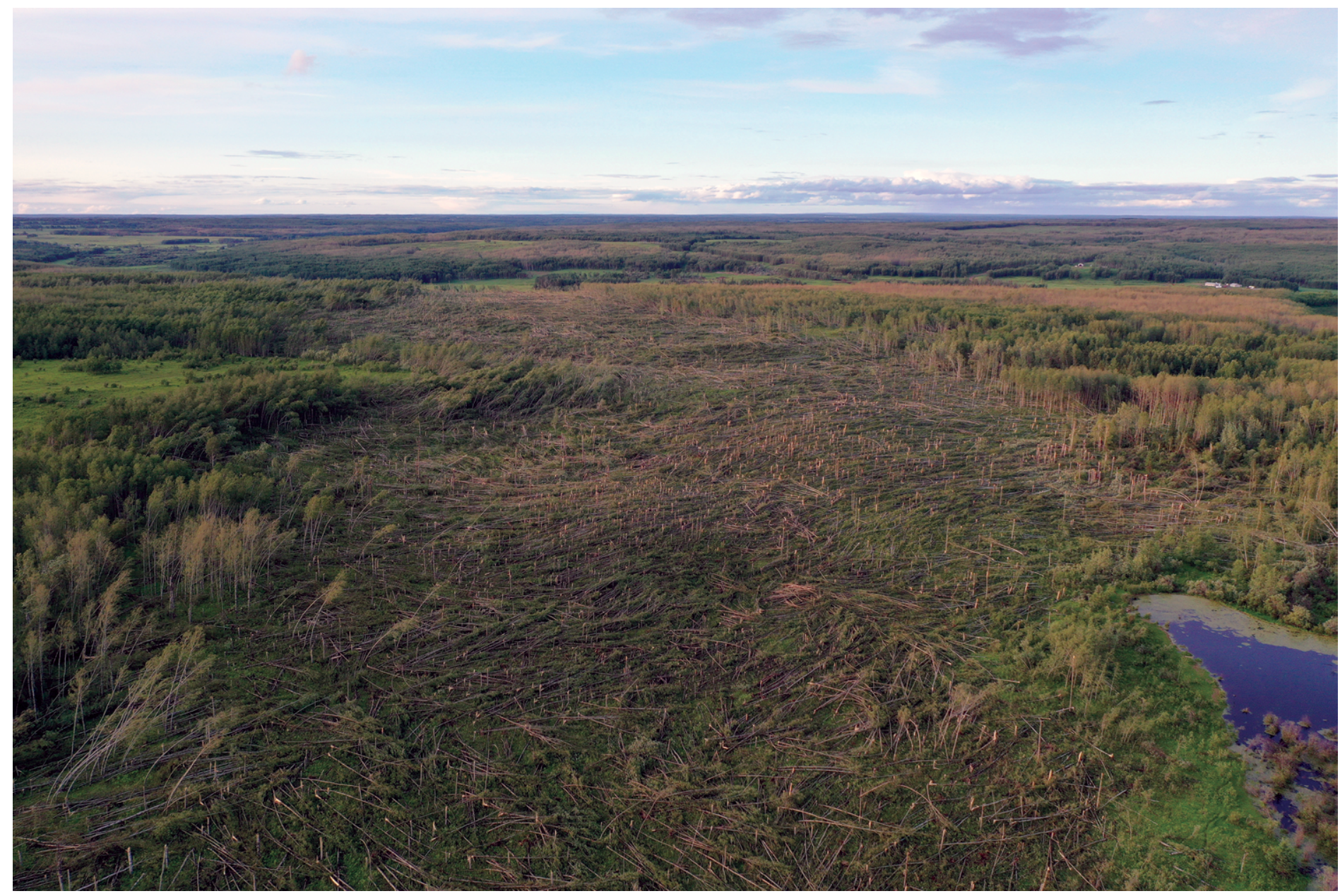

Drone photo of significant forest damage that NTP discovered in central Alberta-looking down the 14.2-km path of the 28 June 2019 EF2 tornado at Buffalo Lake Métis Settlement.

\begin{abstract}
$\mathrm{T}$ ornadoes have resulted in a number of historic catastrophes in Canada. Saskatchewan's Regina “cyclone” of 30 June 1912 left 30 dead and hundreds injured (Lowe and McKay 1962). On 17 June 1946, parts of Windsor, Ontario, were devastated when a tornado south of Detroit, Michigan, crossed the Detroit River and intensified to $\mathrm{F}^{1}$ as it moved northeast, resulting in 17 deaths and close to 100 injuries (Grazulis 2000). While much farther north, Edmonton, Alberta, did not escape a tornado's wrath on 31 July 1987 when an F4 tornado hit the city killing 27, injuring hundreds, and causing $\$ 330$ million $^{2}$ in damage (Alberta Public Safety Services 1990; Charlton et al. 1998). Clearly, understanding the tornado risk across the country is critical for public preparedness, warning strategies, and assessment of potential impacts.
\end{abstract}

Tornadoes have been verified in every province and territory in Canada, although most have been recorded in the southern prairies and southern Ontario (Newark 1984; Sills et al. 2012). These are also regions with some of the country's largest urbanized areas, having high population densities. Intense thunderstorms are known to occur in large and sparsely populated areas of Canada but tornadoes associated with such storms are rarely reported. This results in large gaps in our understanding of the

\footnotetext{
${ }^{1}$ Tornadoes in Canada were rated using the Fujita (F) scale up to the year 2012. The enhanced Fujita (EF) scale was implemented in early 2013 and has been used thereafter.

${ }^{2}$ All loss figures (in Canadian dollars) are relative to the year of occurrence and have not been adjusted.
} tornado climatology.

Though a number of regional tornado studies have been undertaken (see Sills and Joe 2019), Newark (1984) made the first attempt at a national map of average annual tornado frequency 
using an observational database covering the years from 1950 to 1979 and all provinces (Newark 1984, Fig. 2). While maxima were found in parts of the southern prairies and southern Ontario (>1.2 and >2.0 tornadoes per $10,000 \mathrm{~km}^{2}$ per year, respectively), lack of data away from those areas resulted in several odd patterns of higher and lower frequency having little apparent connection to geography or meteorological causes. The exception was an elongated minimum along the Rocky Mountains.

More recently, a study was undertaken to determine Canada's "tornado prone" regions to provide guidance for the National Building Code of Canada. After assembling an updated national database of verified tornadoes, Sills et al. (2012) attempted to fill in gaps due to low population density using statistical modeling with the updated tornado data, lightning density, and population density as inputs. The modeling suggested that 230 tornadoes per year occur in Canada though the observational data showed an average of only $~ 61$ each year.

Utilizing the same observational database, Cheng et al. (2013) used a similar but more conservative statistical modeling approach and estimated that only $\sim 45 \%$ of tornadoes are verified, while also producing a new national map of modeled tornado frequency (Cheng et al. 2013, Fig. 6) that appeared to have a stronger physical basis than that from Newark (1984). In addition to the elongated minimum over the Rocky Mountains, a minimum was also noted to the northeast of Lake Superior, the largest and coldest of the Great Lakes. And while the average annual tornado frequency remained near 2.0 tornadoes per $10,000 \mathrm{~km}^{2}$ per year for parts of southern Ontario, a new national maximum was predicted in southern Saskatchewan topping out above 2.5 tornadoes per $10,000 \mathrm{~km}^{2}$ per year.

Thus, questions remained-Were roughly one-half to three-quarters of tornadoes really not being verified, and if so, were they occurring in the areas predicted by the model? Would enhanced observations support the new location of the predicted national maximum? And what methods could be used to improve the detection of tornadoes in sparsely populated and remote areas of the country? A new national observation effort would be needed to answer such questions.

\section{The Northern Tornadoes Project}

The Northern Tornadoes Project (NTP) was initiated with a focus on improved detection of Canadian tornadoes, particularly in nonurban areas, making use of new and existing sources of data. The goals of the project are to

- enhance our understanding of actual tornado occurrence and risk in Canada;

- test and evaluate new methods for the detection of tornado damage paths, particularly in rural and remote locations; and

- make all data and analyses freely accessible via an open data portal.

The project is globally unique in both systematically collecting tornado and treefall data across the country, and comprehensively analyzing that data with a world-class team of engineers, meteorologists, and experts from other disciplines.

NTP was founded in 2017 as a partnership between Western University and the Torontobased social impact fund ImpactWX. Additional partnerships now include the University of Manitoba, York University, and The Weather Network. NTP also closely collaborates with Environment and Climate Change Canada (ECCC).

In 2017, the main objective was to detect and document at least a few unreported tornado damage paths in the heavily forested regions of Ontario and Quebec-a proof of concept. The scope expanded in 2018 with two objectives-detect and document every EF1+ tornado in Ontario and investigate significant events in other parts of the country. Successes with each of these pilot campaigns resulted in further expansion of the NTP scope in 2019 to the detection and documentation of all tornadoes across Canada. 
Western Libraries has developed an open data portal for the display of and access to NTP data (photos, aerial imagery, satellite imagery, event data) and analyses. The site is linked through GIS-all data can be linked to other data through location information. There is also a graphical dashboard that allows users to plot and browse events using a map and various filters.

Finally, an international team of researchers has been assembled via NTP to push the boundaries of tornado damage detection and intensity assessment via remote sensing, with expertise in trees, crops, and soil as well as advanced artificial intelligence (AI) methods. This team meets annually to share results and assess future directions.

\section{Data and methods}

A multistep tornado event detection, analysis, and documentation process has evolved with NTP over its first three years. These steps are described in detail below in the general order that they are taken for each event. Note that some of the steps may occur in parallel as necessary, and that the process will likely continue to evolve as additional experience is gained and technology advances.

Tornado outlooks. Daily forecasts of tornado potential enable NTP team readiness, by both heightening the awareness of research staff observing events in real time and providing ground survey teams with advance notice of potential deployment.

By the 2019 NTP campaign, this process had evolved to a rotating team of three meteorologists producing tornado outlooks daily from June through August, and on an as-needed basis in the shoulder months. The duty forecaster identifies tornado potential on Day 2 (i.e., the following day) with updates to risk levels and areas for Day 1 when warranted.

When a "likely tornado" risk or "chance tornado outbreak" is identified, a regional map is included with an expanded text summary discussing expected parent-storm type and key environmental parameters. In addition, the outlook graphic is shared via NTP's social media channels. An example from 21 August 2019 is provided in Fig. 1, where the Day 2 outlook illustrates a "likely tornado" risk in southern Quebec.

Storm track identification. After intense thunderstorms have occurred, Doppler radar imagery is used to identify storm track locations and storm types. Of particular interest are supercell storms since these can be long lived (up to $\sim 2 \mathrm{~h}$ or even longer) and are responsible for the vast majority of strong and violent (EF2-EF5) tornadoes
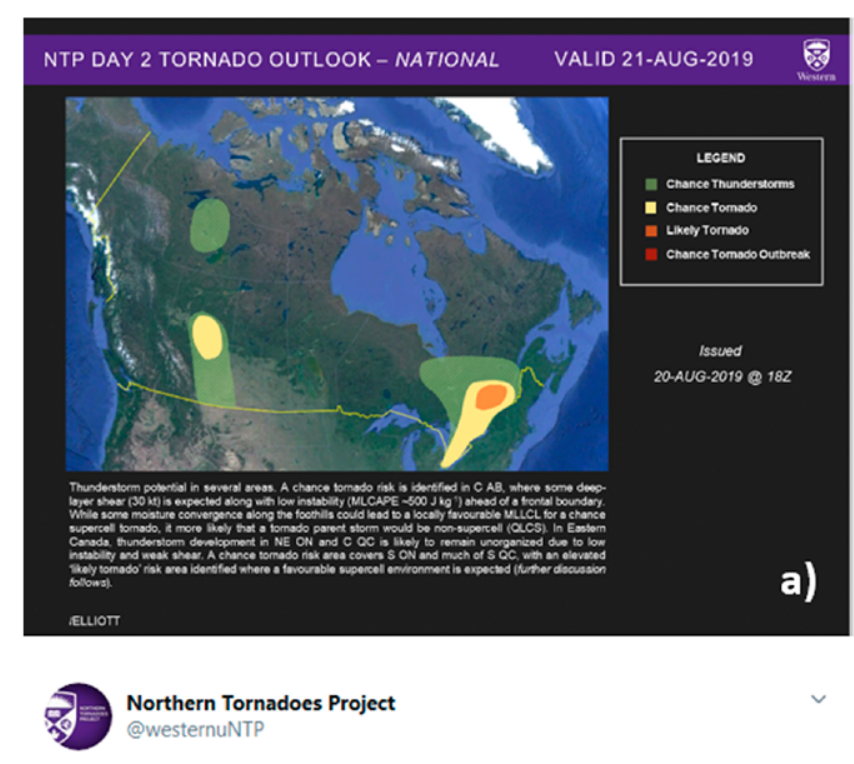

Northern Tornadoes Project @westernuNTP

@westernuNTP meteorologists produce internal outlooks in order to ensure ground teams are prepared. On days with a 'likely' or greater area on our map, we will share here. And that is the case for tomorrow in southern QC. Note: experimental and not intended for operational use

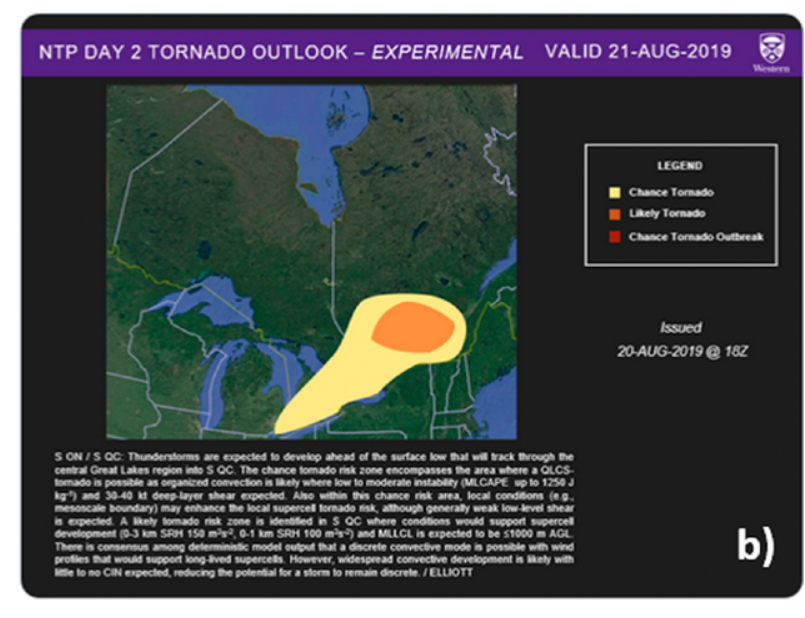

4:07 PM · Aug 20, 2019 - Twitter Web App

Fig. 1. (a) NTP experimental Day 2 national tornado outlook for 21 Aug 2019, and (b) NTP regional outlook for 21 Aug 2019, including more detailed discussion of "likely"-area meteorology, as posted to Twitter. Four supercell tornadoes (three EF2 and one EF1) developed in the "likely tornado" risk area and one EF1 supercell tornado developed in the "chance tornado" risk area. 
(Markowski and Richardson 2010). However, tornadoes associated with quasi-linear convective systems (QLCS; see Schenkman and Xue 2016) and so-called landspout tornadoes (Wakimoto and Wilson 1989) make up a large fraction of tornadoes each year and are also of interest.

Particular radar signatures that help to identify storm type and intensity are sought, including weak-echo regions, hook echoes, and bow echoes from radar reflectivity, and mesocyclones and QLCS mesovortices from radar radial velocity (see Markowski and Richardson 2010). The presence of a tornado can even sometimes be detected where dual-polarization radar data are available via a “tornado debris signature” (e.g., Van Den Broeke and Jauernic 2014). In the large regions of Canada outside of radar range, geostationary satellite imagery can be used to identify intense updrafts, for example, by identifying overshooting storm tops (e.g., Mikuš and Mahović 2013) as well as linear versus discrete storm types and storms showing a deviant right-moving motion (see Markowski and Richardson 2010). Lightning data from various platforms and sources can also be used to complement the radar and satellite data.

Another key source of data at this stage is crowdsourced reports, typically collected via social media channels (primarily Twitter and Facebook). They may be vague or even inaccurate initially but often give an idea of where the most intense damage has occurred and whether the damage appears to be widespread or narrowly focused, with the latter being more likely to be related to tornado occurrence. Sometimes, such reports are the only immediate indication that a tornado may have occurred.

A set of Twitter hashtags, one for each province and territory, has been introduced so that tweets with tornado reports can be directed to the NTP team (e.g., \#onNTP in Ontario, \#abNTP in Alberta). NTP also has a "Report a Tornado" section on its website that aims to empower the general public to become citizen scientists and report their observations to us through an online web form.

The NTP team will often follow up with the primary information source to ensure legitimacy and accuracy. Maps indicating the estimated storm track with embedded text and images are then constructed.

Ground and drone surveys. Though ground surveys have been a fundamental method for gathering storm damage information for decades, methods here have also undergone considerable change. Highly detailed engineering studies are now often undertaken for significant events (e.g., Kopp et al. 2017), with new tools for capturing ground-based damage data. Examples are lidar and drone imagery at the building and building-component scale (Womble et al. 2018), and new approaches to engineering analysis of both damage (Sudha et al. 2012) and wind speeds (Lombardo et al. 2015). These new approaches take advantage of developments in the understanding of tornado wind fields (Kosiba and Wurman 2013; Baker and Sterling 2018; Refan and Hangan 2016, 2018), building aerodynamics in tornadoes (Haan et al. 2010; Hu et al. 2011; Kopp and Wu 2017), and building performance under extreme wind loads, particularly for houses (Ramseyer et al. 2014; van de Lindt et al. 2013).

NTP ground surveys are conducted by trained wind engineers and meteorologists (Fig. 2a). Because damage is often cleaned up within a day or two of the event, including clues that may be key to understanding the type and intensity of the wind phenomenon, the ground survey team needs to be on site as soon as possible after the event.

There are two complementary objectives during ground surveys. One is "operational"-to determine the damaging wind phenomenon and assign an EF-scale rating, and document the length, maximum width, and other characteristics using established guidelines.

The second objective is to conduct a "research" investigation/engineering analysis to identify failure modes and estimate wind speeds using the latest engineering knowledge. Ground surveys are often the only method for obtaining the required information. Note 
that the results from each type of investigation may not entirely agree. The intention is that cumulative results from the research investigations will eventually improve the accuracy of future operational guidelines.

An NTP ground surveying application was developed by Western Libraries that ensures efficiency, accuracy, and consistency. This app, installed on tablets and cell phones, is used by surveyors to quickly record site information and take photographs, linking data to the GPS-derived location of the event with its name, degree of damage, estimated wind speed, type of damage, and more. This app also immediately sends information back to the main server that can be viewed remotely.

Drones have been increasingly used to improve tornado data, typically recording images and video on the neighborhood scale (Womble et al. 2018). Unlike satellite imagery, drone imagery remains useful even with considerable cloud cover or haze/ smoke over the area of interest. Advances in drone technology now allow more extensive and semiautomated modes, with the stitching of thousands of images to create orthomosaic maps of storm damage having a spatial resolution down to $1 \mathrm{~cm}$ (Wagner et al. 2019). Adjustments are made for topographic relief, lens distortion, and camera tilt so that the scale of the image is uniform and follows the given map projection [American Society of Civil Engineers (ASCE); ASCE 1994]. NTP ground surveyors used drones to take along-track video and single aerial photographs of damaged forests and structures in 2018 (Fig. 2b), and added the ability to use preprogrammed flight paths for the generation of high-quality orthomosaic maps in 2019.

Satellite imagery and analysis. The first attempt to use satellite imagery to detect and document tornado damage in the boreal forest was made in Canada in the 1970s using images from the sun-synchronous Landsat Multispectral Scanner with a nominal spatial resolution of $60 \mathrm{~m}$ (Sayn-Wittgenstein and Wightman 1975). A number of studies in the United States have examined tornado damage using satellite imagery (Yuan et al. 2002; Jedlovec et al. 2006; Molthan et al. 2014). More recent attempts in northeast Europe using Landsat data uncovered 105 previously unreported tornadoes that occurred between 2000 and 2014 (Shikhov and Chernokulsky 2018).

When a ground survey is not possible due to lack of access to a location, high-resolution satellite imagery becomes the primary tool for the preliminary characterization of the damage. NTP uses a commercial vendor known as Planet Laboratories, and their imagery has become a key tool for NTP
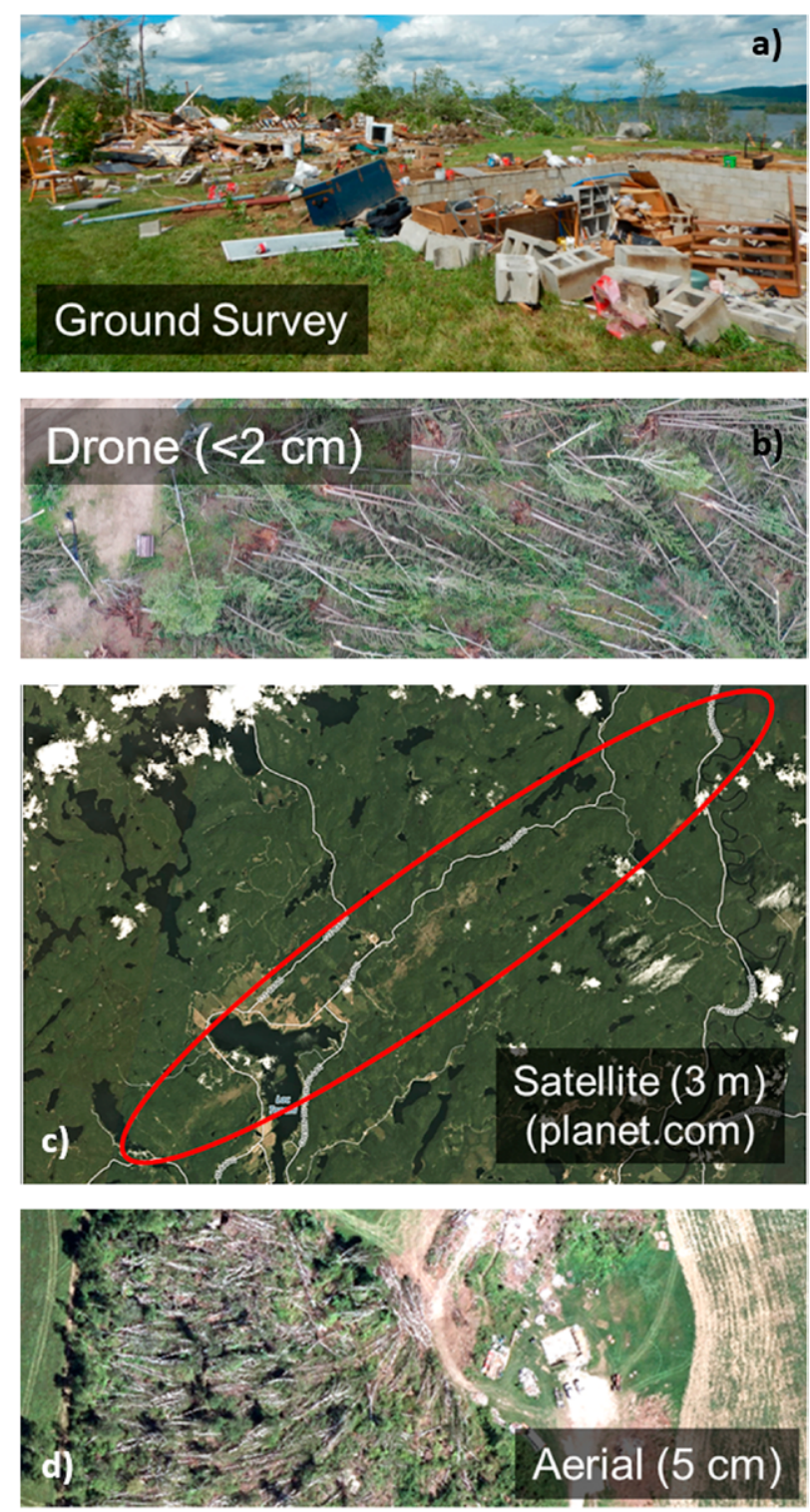

Fig. 2. (a) Ground survey photo of residence removed from foundation, (b) drone image of snapped and uprooted trees of various species, (c) highresolution satellite imagery showing the full path of a tornado (circled in red), and (d) aircraft aerial imagery of destroyed residence and nearby trees. Images in (a), (c) and (d) are from the 18 Jun 2017 EF3 tornado at Sainte-Anne-du-Lac, Quebec. Image in (b) is from the 29 Jun $2019 \mathrm{EF} 2$ tornado at Lac des lles, Saskatchewan. 
analysis-able to provide visible spectrum imagery with 3-5-m nominal resolution over a given location on a quasi-daily basis. This level of detail makes significant tree damage in forests immediately apparent (Fig. 2c). Even tornado damage across agricultural fields can leave telltale visual cues, although these continue to be investigated for their intensity assessment potential. NTP has also made use of Planet Laboratories' enhanced-resolution (initially $80 \mathrm{~cm}$, now $50 \mathrm{~cm}$ ) imagery for specified areas of interest from a smaller fleet of "SkySat" satellites.

There are a number of guidelines that have been developed to distinguish tornadic damage from downburst damage using remote sensing imagery. They include the following:

- major areas of forest damage are aligned (line or gentle curve), with no along-path gaps greater than $3 \mathrm{~km}$

- aspect ratio of aligned damage path approaches or exceeds 10:1

- path width less than $2 \mathrm{~km}$ (with rare exceptions), and total length at least $1 \mathrm{~km}$

- can be a wider area of minor nontornadic damage in the vicinity but mostly to one side of the tornado damage path (i.e., related to a supercell rear-flank downdraft)

Satellite imagery (Planet Laboratories back to 2009, Google Earth back to 1984) is also being used by NTP to manually and systematically search regions across Canada for past undocumented tornadoes. Results to date include 140 potential new tornadoes found using this approach, dating back to 1987. However, generally the further in the past the event, the harder it is to associate a specific event date and time. For the 1987 event, all that can be determined at this point is the year and season of occurrence. Detailed methods and final results here will be described in a future publication.

Aircraft aerial imagery and analysis. After preliminary damage paths are identified using all of the above information and ground/drone surveys have been performed, aircraft aerial flights are required for any remaining areas thought to have damage but not reachable by drone. Areas of interest are passed on to NTP's flight vendor, KBM Resources Group, and flights are then scheduled. Georeferenced imagery with $5-\mathrm{cm}$ nominal resolution is typically obtained and processed (Fig. 2d). The high-resolution imagery, when imported into GIS software (NTP uses ArcGIS), allows detailed investigations of tree damage (e.g., directions that trees are down, character of root ball, ground conditions, tree species), path lengths and widths, and damage intensity.

This step in the process currently takes the longest time to complete. The flights are sometimes conducted weeks after the event, and the processed data typically take weeks to arrive and longer to manually analyze. Ways in which to reduce such delays are being investigated, including the automation of treefall analysis (see sidebar discussion).

Classification and rating. From the collected data, event classification and rating decisions must be made using the latest scientific understanding of severe weather phenomena.

When damage is present, the likelihood that the damage was caused by a tornado versus a downburst (or gustnado) is assessed. In cases where it is unclear which is more likely given the available evidence (usually only weaker events), "unclassified wind damage" is used. The damage is further characterized by estimating the path length and maximum width.

When only visual evidence of a vortex is available, the likelihood that it is a tornado or a nontornadic vortex (NTV) must be assessed. The NTV classification includes subtornadic vortex (surface wind speeds less than the threshold for EF0), vortex-funnel cloud aloft, gustnado, and dust devil.

Waterspouts, defined as tornadoes over water, have historically not been included in Canadian tornado datasets for large bodies of water (i.e., at least $10,000 \mathrm{~km}^{2}$ ). This is mainly 


\section{Automation of treefall identification-Preliminary results}

Manual treefall identification is tedious, slow, and costly. Even partial automation of treefall detection using remote sensing imagery would be beneficial. Automation may also be important for tornado intensity estimation based on patterns of treefall (e.g., Lombardo et al. 2015). Deep learning techniques have recently been applied to aerial damage data from drones (Mohammadi et al. 2019). For NTP, preliminary work using deep neural networks and 2-cm drone imagery from the EF4 Alonsa, Manitoba tornado in 2018 has been promising, as described below.

Ten drone images (4,056 × 3,040 pixels at 72-dpi resolution) were chosen with each including a mix of healthy and fallen trees. These images were further processed and segmented and then labeled with VGG Image Annotator (Dutta and Zisserman 2019) to generate the ground truths.

The resulting annotated images were divided into two batches - training and validation—and passed into the neural network to perform instance segmentation. Using the Mask region-based Convolutional Neural Network (Mask R-CNN; He et al. 2020) framework, the image was subjected to a four-step process to identify the fallen trees. The image was first passed into a backbone layer to generate a feature map that was further enhanced through the Feature Pyramid Network. Anchors were detected using a slidingwindow method to find treefall damage and further refined. These final regions of interest were passed to the classifier and bounding box regressor where adjustments were made to the location and size of each box. In the final step, a segmentation mask is applied to each downed tree and scaled back up to the size of our original image. Each mask can then be separated individually into bitmasks to determine the total number of trees detected. Finally, using the Hough transform, the angle of each bitmask can be calculated.

After training over the sample dataset of around 500 trees for three epochs of 30 steps each at a learning rate of 0.001 and filtering the minimum detection confidence to $80 \%$, our program successfully identified around $68 \%$ of trees in the validation dataset. Detection output can be seen in Fig. SB1, where most discernible trees are identified in the given image.

As our approach is fairly novel and no similar study has been conducted using deep learning on treefall pattern recognition, there is potential for a lot of improvement. One such area would be to label more ground truth data for the Alonsa tornado, and parse over the entirety of the orthomosaic map's constituent TIFF files to compare with the precomputed data. Given that drone imagery resolution in stitched orthomosaics is the same as that of the pictures, a similar process could be achieved by splitting an ArcMap TIFF file into individual images.

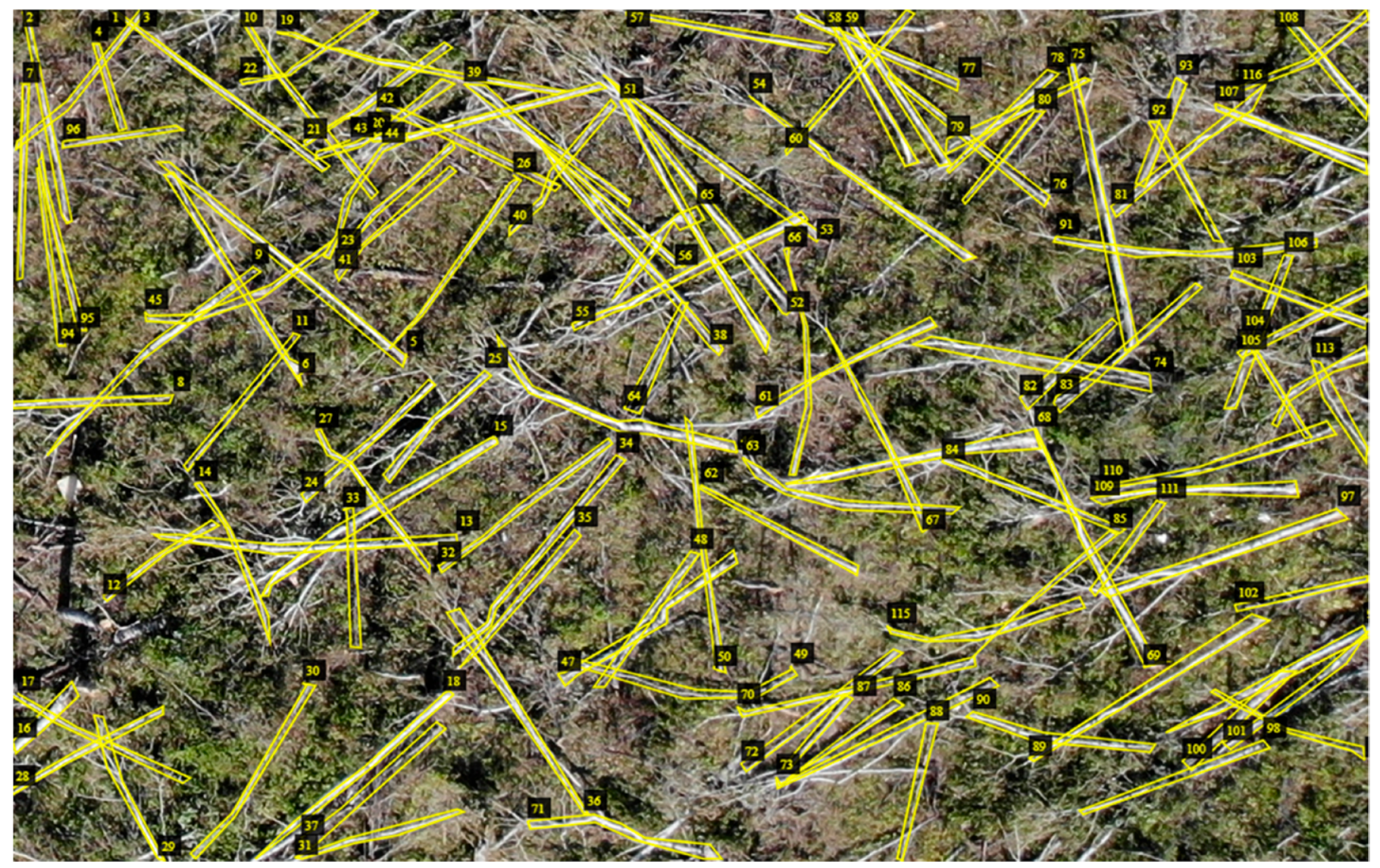

Fig. SB1. Results from the deep neural network showing 116 correctly identified fallen trees (numbered yellow outlines). There are actually 124 fallen trees in the image. 
due to ECCC program jurisdiction issues (public versus marine programs). Practices by the U.S. National Weather Service have been similar (NOAA 2018). NTP now includes these tornadoes in our datasets on an experimental basis, but not in annual tornado statistics for the time being.

The Canadian version of the EF scale, implemented on 1 April 2013, is used to rate the intensity of the damage caused by a tornado (or downburst), based upon an estimated maximum wind speed (Sills et al. 2014). The Canadian EF scale uses 31 different "damage indicators" (DI; e.g., buildings, trees, electrical transmission structures). Each damage indicator has associated "degrees of damage" that range from the threshold of visible damage to total destruction. Each degree of damage has an associated wind speed range from which a representative maximum wind speed is estimated. The EF-scale rating (between 0 and 5) is then assigned based upon the estimated maximum wind speed (Mehta 2013).

A method has been developed by NTP to enable consistent EF-scale assessments of forest damage. The Trees DI in the Canadian implementation of the EF scale uses a "population based" approach that requires estimating the percentage of snapped and/or uprooted trees along the tornado damage path. NTP's "forest box method" involves using sample boxes along the damage path to estimate that percentage. The appendix provides further details on the method.

When only visual evidence of a tornado is available, and no damage is caused to an EF-scale damage indicator, a rating of EF0-default is assigned. This indicates that a wind speed of at least $90 \mathrm{~km} \mathrm{~h}^{-1}$ (the lower bound of EFO using the Canadian EF scale) is expected to have occurred. The actual wind speed can be considerably higher, particularly on the prairies where even large, intense tornadoes can sometimes fail to encounter a DI.

After a tornado or downburst has occurred, preliminary assessment results are typically desired for media and public information purposes within 24-48 h of an event. Given ECCC distributes this type of information via storm summary bulletins, there is often discussion between ECCC and NTP on the preliminary assessment before it is broadcast.

After the preliminary assessment has been disseminated publicly, there is usually weeks to months more work for NTP collecting all possible evidence and reassessing the event as new evidence becomes available. All working data are shared with ECCC. Once all evidence is considered, NTP determines a final assessment with each approved by NTP's Executive Director.

Open data portal. The Northern Tornadoes Project "open data" website was created to serve as a public access portal for the project's data. An interactive dashboard allows users to filter and plot events (an example is shown in Fig. 3). Occurrence totals are provided along the top in bold text. Upon clicking on an event icon, a text box provides event details and a link to images and analysis. Eventually historical data from pre-NTP years will be included, all the way back to Canada's first recorded tornado in 1792 (Etkin et al. 2001).

\section{Project results}

NTP tornadoes and other events. NTP investigations for the initial pilot campaign, focused on the forested regions of Ontario and Quebec, began in mid-June of 2017 while the last aircraft flight was made near the end of October. Additional 2017 tornadoes were found during investigations in 2018 and 2019. A total of 33 tornadoes were investigated and verified (Fig. 4), and 23 of those would not have been discovered without NTP-an increase of 230\% (Table 1). The documentation for the remaining 10 tornado events was improved through EF-scale upgrades, more accurate length and width assessments, and the collection of research-quality data. Of the 33 tornadoes, 20 occurred during a multiday tornado outbreak in Quebec over 17-18 June (to be discussed later in the "Significant event summaries" section).

Though the 2018 tornado season started quite late (first tornado of the season on 13 June) and ended somewhat early (last tornado on 25 September), it was a busy one with a number of significant events, including a 14-tornado outbreak in forested regions of southern Quebec and a 


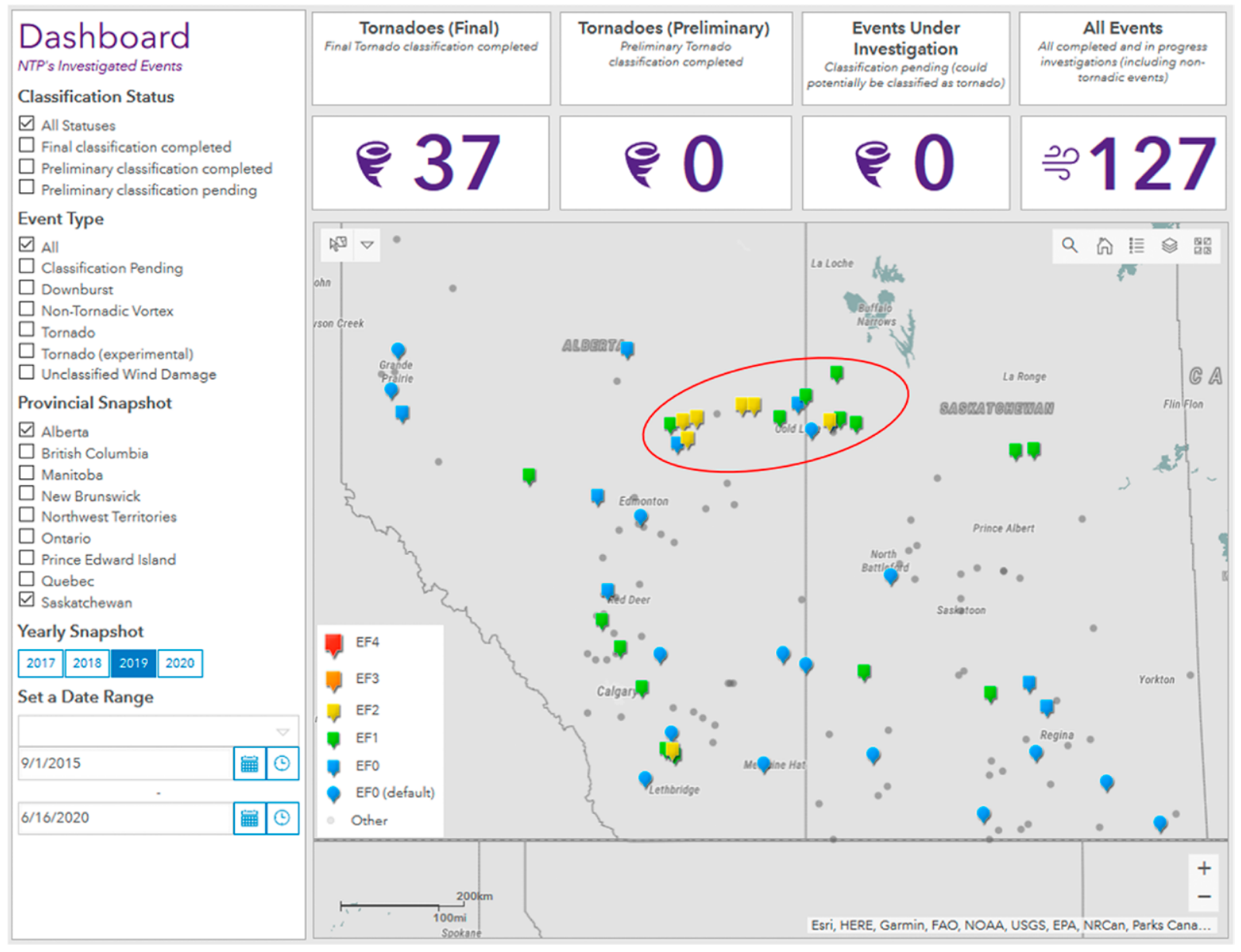

Fig. 3. "Interactive dashboard" image showing the locations of all NTP-classified tornadoes, downbursts, nontornadic vortices, and events with unclassified wind damage in Alberta and Saskatchewan in 2019. Assessed damage intensities are shown using icons colored by EF rating. Gray dots represent nontornadic vortex events. "Preliminary" and "under investigation" totals are typically nonzero as events are investigated through the storm season. The locations of events for the 28-29 Jun 2019 tornado outbreak, plus three tornadoes from 24 Jul 2019 along the southern periphery, are circled.

late-season, 7-tornado outbreak on 21 September that caused up to EF3 damage in and around the nation's capital, Ottawa. For the latter event, there were 23 injuries (a few serious) and hundreds of structures were damaged or destroyed, including homes, apartment buildings, commercial buildings, farm buildings, and electrical stations and towers, with insured losses estimated at close to $\$ 300$ million by the Insurance Bureau of Canada (IBC; IBC 2018). The insured losses also make it one of the most expensive tornado events in Canadian history. Finally, this event occurred quite late in the season-there had been only one other recorded EF3 tornado in Canada in September or later and that was pre-1900 (Merritton, Ontario, 26 September 1898).

Also of note in 2018, an EFO tornado verified by NTP in the province of British Columbia was the only tornado recorded in British Columbia's Lower Mainland since 1991. NTP verified the occurrence of 55 tornadoes in total, with 9 of those occurring outside of Ontario and Quebec (Fig. 5). Since Quebec had such an active tornado season, the focus for 2018 ended up being split between Ontario and Quebec. Of the 46 tornadoes in those provinces, 34 of them were verified by NTP and would

Table 1. Events classified by NTP in 2017, 2018, and 2019.

\begin{tabular}{|lllll|}
\hline & 2017 & 2018 & 2019 & Total \\
Tornado & 33 & 55 & 66 & 154 \\
Tornado (experimental) & 0 & 9 & 5 & 14 \\
Downburst & 0 & 28 & 45 & 73 \\
Nontornadic vortex & 0 & 38 & 89 & 127 \\
$\begin{array}{l}\text { Unclassified wind } \\
\text { damage }\end{array}$ & 0 & 8 & 15 & 23 \\
Total & 33 & 138 & 220 & 391 \\
\hline
\end{tabular}


otherwise have gone undocumented-an increase of $283 \%$. The verified events for 2018 are shown in Table 1, including tornadoes, "experimental" tornadoes, downbursts, nontornadic vortices, and unclassified wind damage.

The length of the 2019 tornado season at roughly 6 months was far more typical than that for 2018, with the first tornado recorded on 24 April and the last on 19 October. A significant tornado outbreak occurred in Alberta and Saskatchewan on 28/29 June, and those events will be discussed in more detail in the "Significant event summaries" section. In

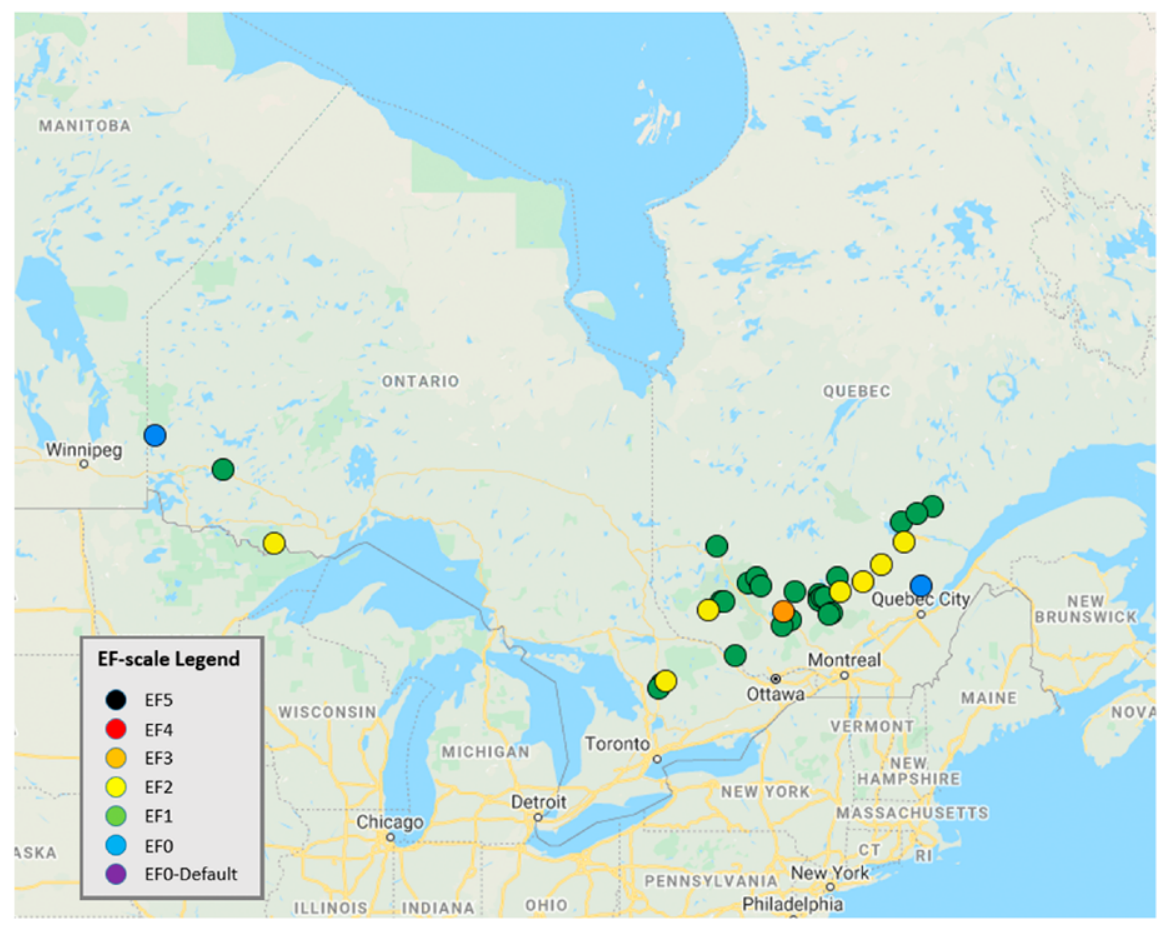

Fig. 4. 2017 NTP tornadoes by EF scale. All tornadoes were located in Ontario and Quebec. Map data $\odot 2020$ Google. addition, the first Canadian ground survey north of $60^{\circ} \mathrm{N}$ documented damage from a very rare Northwest Territories tornado. NTP verified the occurrence of 66 tornadoes in total across Canada (Fig. 6). Of these, 29 were discovered by NTP and would otherwise have gone undocumented-an increase of 78\%. All verified events for 2019 are also listed in Table 1.

Overall, since 2017 the project has investigated, verified, and documented 154 tornadoes, including 89 tornadoes that otherwise would not have been identified.

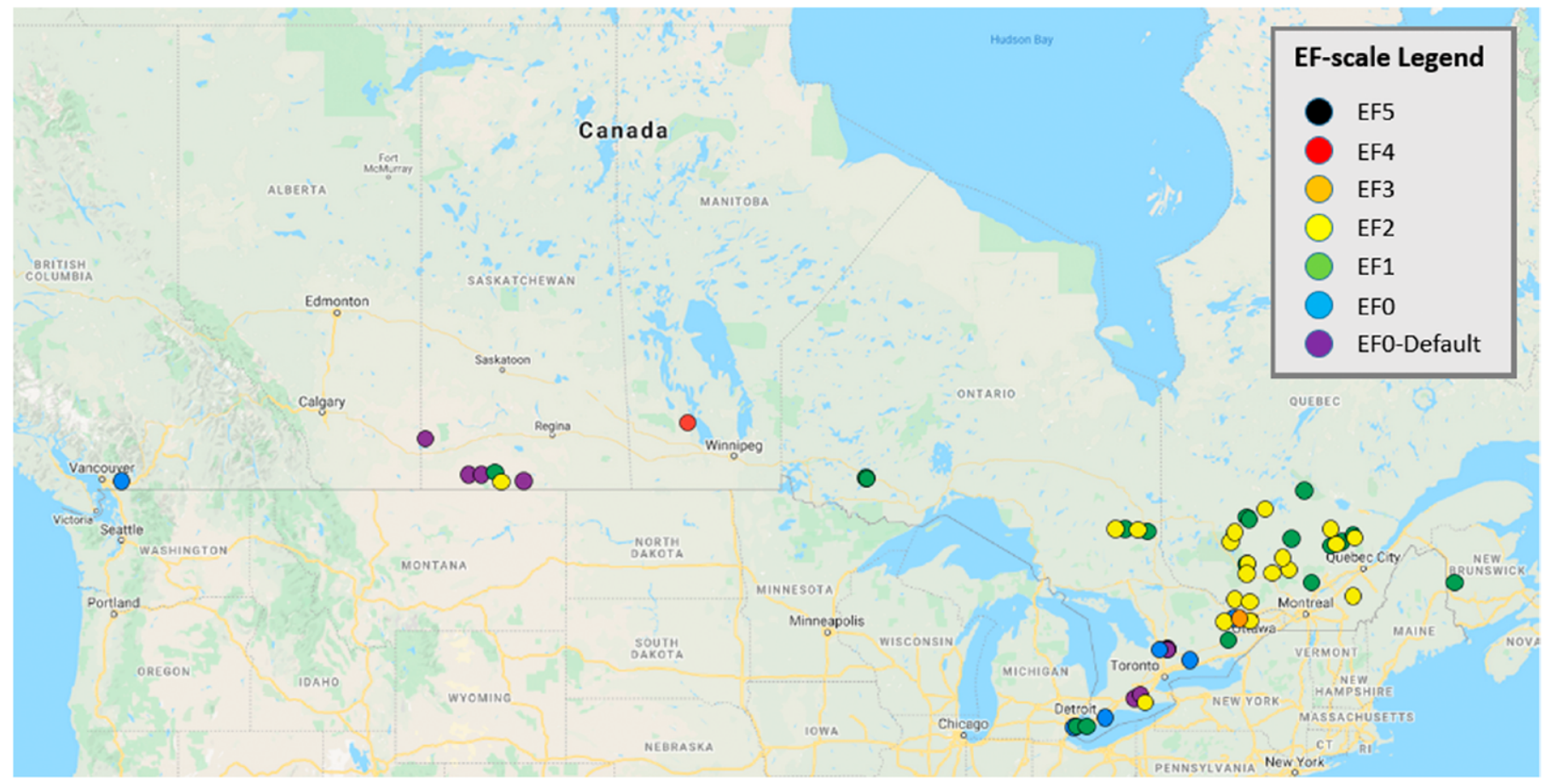

Fig. 5. 2018 NTP tornadoes by EF scale. All tornadoes were located in Ontario and Quebec, New Brunswick, Manitoba, Saskatchewan, and British Columbia. Map data @2020 Google. 


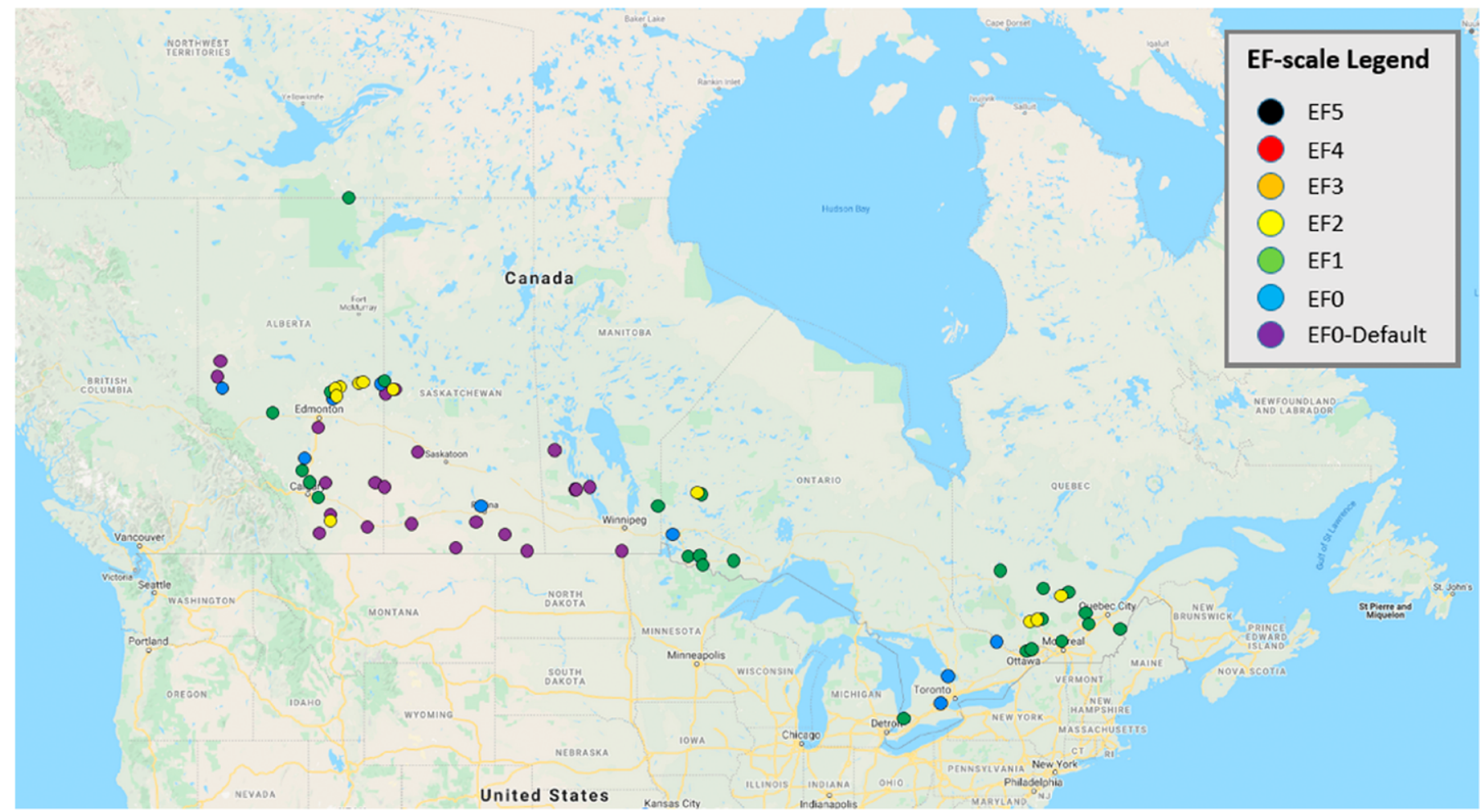

Fig. 6. 2019 tornadoes by EF scale. All tornadoes were located in Northwest Territories, Alberta, Saskatchewan, Manitoba, Ontario, and Quebec. Map data @2020 Google.

Significant event summaries. There were a number of climatologically extreme tornado events that occurred in NTP study areas during the 2017-19 campaigns, and these are discussed in limited detail below.

JUNE 2017 MULTIDAY tORNADO OUTBREAK. Four waves of supercell thunderstorms crossed southern Quebec on 17 and 18 June 2017 producing large hail, high winds, and damaging tornadoes. There were two injuries, and losses are conservatively estimated by NTP to be near $\$ 500,000$. Initial investigations determined that four tornadoes occurred on 18 June. Ground surveys were conducted by NTP at multiple locations in Quebec. The most impressive damage was found at Sainte-Anne-du-Lac (see Figs. 2a,c,d). A chalet-style residence was destroyed with only the basement foundation remaining in place. Treefall in the area was also extensive. The damage here was assessed at EF3. The length and maximum width of the damage path were estimated at $30.5 \mathrm{~km}$ and $1,300 \mathrm{~m}$, respectively.

Using Planet Laboratories satellite imagery (for the first time in Canada for this purpose) over the known damage locations, as well as surrounding areas, NTP exhaustively studied the region affected by the supercells (spanning more than $100,000 \mathrm{~km}^{2}$ ) to isolate any previously unknown forest damage. In addition, high-resolution aircraft aerial imagery was collected and analyzed for five of the tornadoes. As a result, 7 new tornadoes were identified, raising the total number of confirmed tornadoes for the southern Quebec outbreak to 11.

Satellite review of events in 2019 near the same area resulted in additional tornadoes being found-3 from 18 June 2017 and 6 from storms during the previous evening roughly $200 \mathrm{~km}$ to the west. The 2-day outbreak, which includes 20 tornadoes with damage rated at EF0 (1), EF1 (13), EF2 (5) and EF3 (1), is the largest recorded to date in Quebec and one of the largest recorded in Canada.

This was the first of three tornado outbreaks affecting this part of Quebec. In 2018, a 14-tornado outbreak occurred on 5 September with up to EF2 damage, and on 21 September a 7-tornado outbreak affected the larger national capital region around Ottawa, including 4 
tornadoes in Quebec. The strongest tornado there produced EF3 damage. The start locations, tracks, and EF-scale ratings of all tornadoes in the three outbreaks are shown in Fig. 7.

August 2018 EF4 tornado. On 3 August 2018, near 2000 local time (CDT), a violent tornado developed in southern Manitoba affecting the small community of Alonsa (Fig. 8). The tornado caused catastrophic damage along a path at least $15.7 \mathrm{~km}$ long and 1,200 m wide. The tornado caused one fatality and a few injuries. Losses were conservatively estimated by NTP to be near $\$ 2$ million.

The NTP ground survey team found that several homes were destroyed and swept off their foundations. While normally this would result in an EF5 rating, it was determined that the construction quality prevented a rating above EF4. Large trees were ripped from the ground and thrown a considerable distance. Vehicles were also tossed. NTP acquired additional high-resolution imagery from both satellite and aircraft platforms.

At EF4, this was the highest-rated tornado damage in North America (and likely the world) in 2018. It was also the first tornado rated at EF4 following the implementation of the new Canadian EF scale, and the first F/EF4+ tornado in Canada since the 2007 F5 tornado at Elie, Manitoba (roughly $100 \mathrm{~km}$ to the southeast).

JUNe 2019 MULtidAY TORNAdO OUTBREAK. Over 28 and 29 June, 11 tornadoes developed in Alberta and Saskatchewan, with the majority of the tornadoes occurring in the Cold Lake region near the provincial border. Nine of those tornadoes occurred on 28 June with up to EF2 damage (an additional more northerly tornado from 28 June has been found via the systematic satellite search described earlier but is not counted here). The remaining three occurred the following day, again with up to EF2 damage. Tornado locations are shown in Fig. 3. Ground survey, drone, satellite, and aircraft aerial imagery were collected and analyzed in order to characterize the tornado damage (Figs. 2b and 9).

This multiday outbreak was the most significant tornado event of the 2019 season across Canada, and ranks among the largest outbreaks on record for western Canada. Damage occurred mostly in forested areas, though several farms were affected, and most of the trees in a campground were flattened. There were no known injuries and though damage losses were low, the exact figures are unknown.

\section{Discussion}

In this section, we compare the characteristics of NTPverified tornadoes in the NTPCA dataset (2017-19) to that of tornadoes from the 30-yr national (30YCA) dataset (1980-2009), including damage intensity as well as

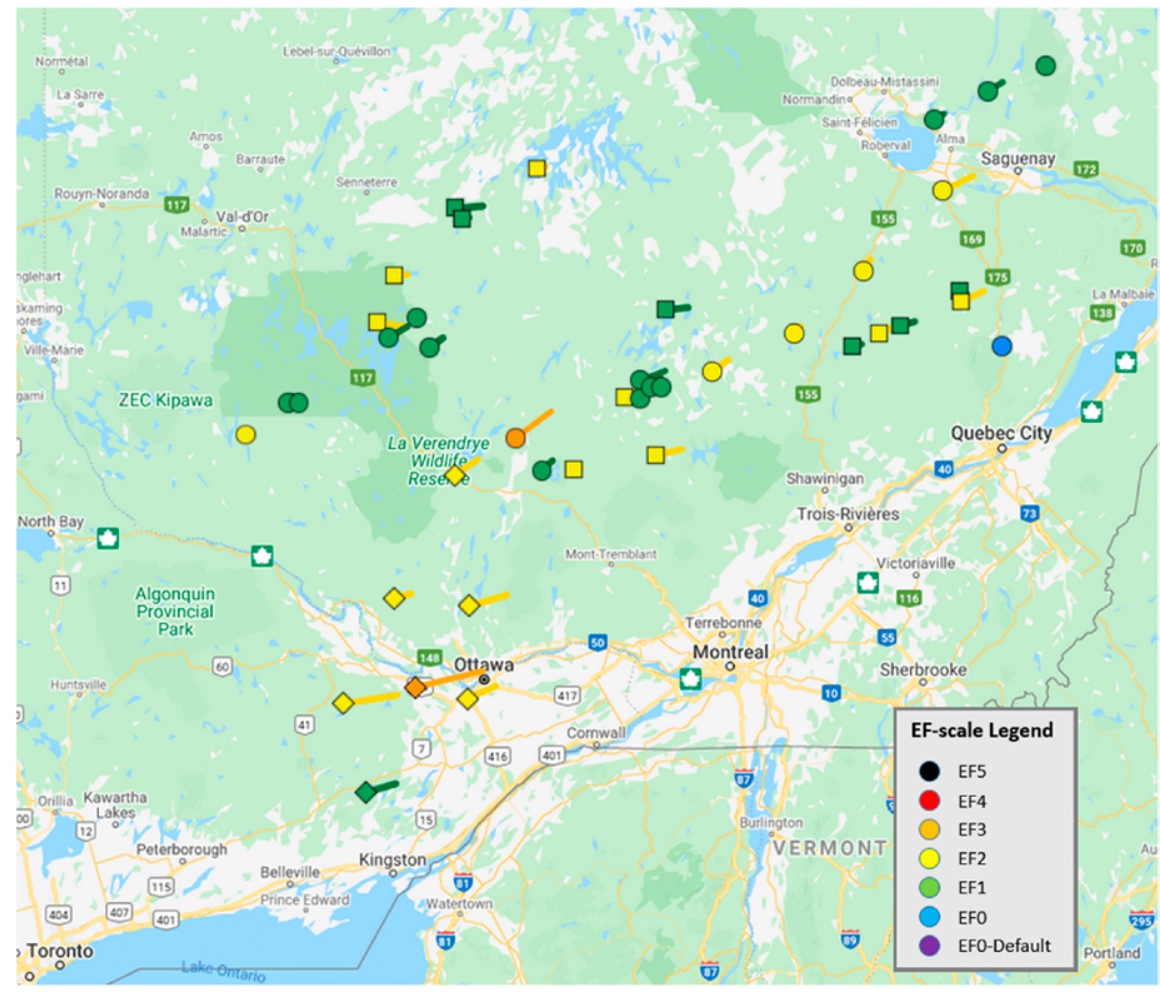

Fig. 7. Map showing three tornado outbreaks: 17-18 Jun 2017 in southern Quebec (squares), 5 Sep 2018 in southern Quebec (circles), and 21 Sep 2018 in eastern Ontario and southern Quebec (diamonds). Map data $\odot 2020$ Google. 


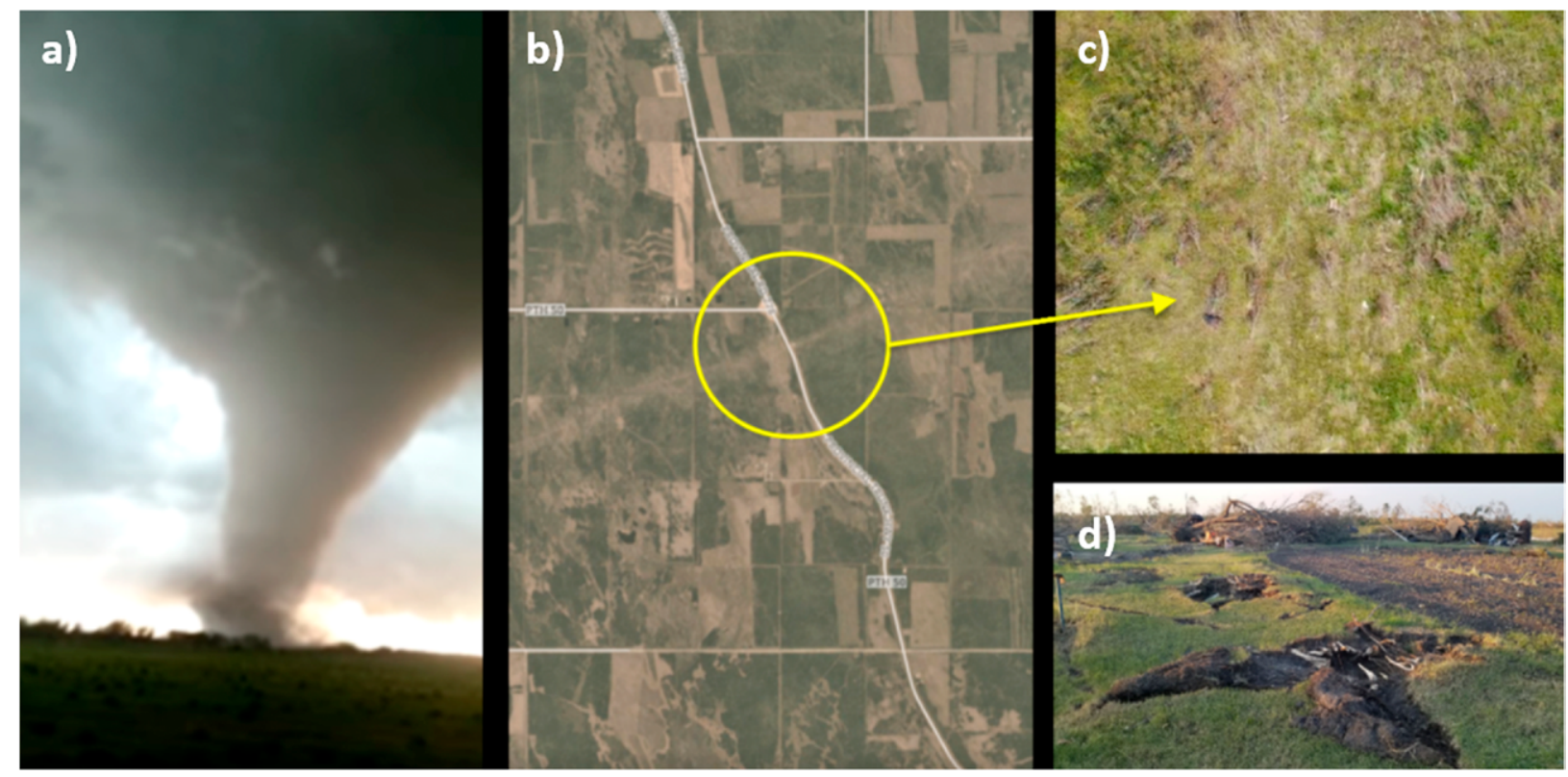

Fig. 8. Images from the 3 Aug 2018 EF4 Alonsa tornado in Manitoba: (a) video capture of tornado near Alonsa (Shawn Cabak/Facebook, used with permission); (b) high-resolution satellite image showing tornado path through cropland, grassland, and woodlots; (c) drone image showing small fallen trees and discolored grasses that appear in the satellite imagery (yellow circle and arrow); and (d) large trees ripped from the ground and moved to the far end of the field (Kyle Brittain/The Weather Network, used with permission).
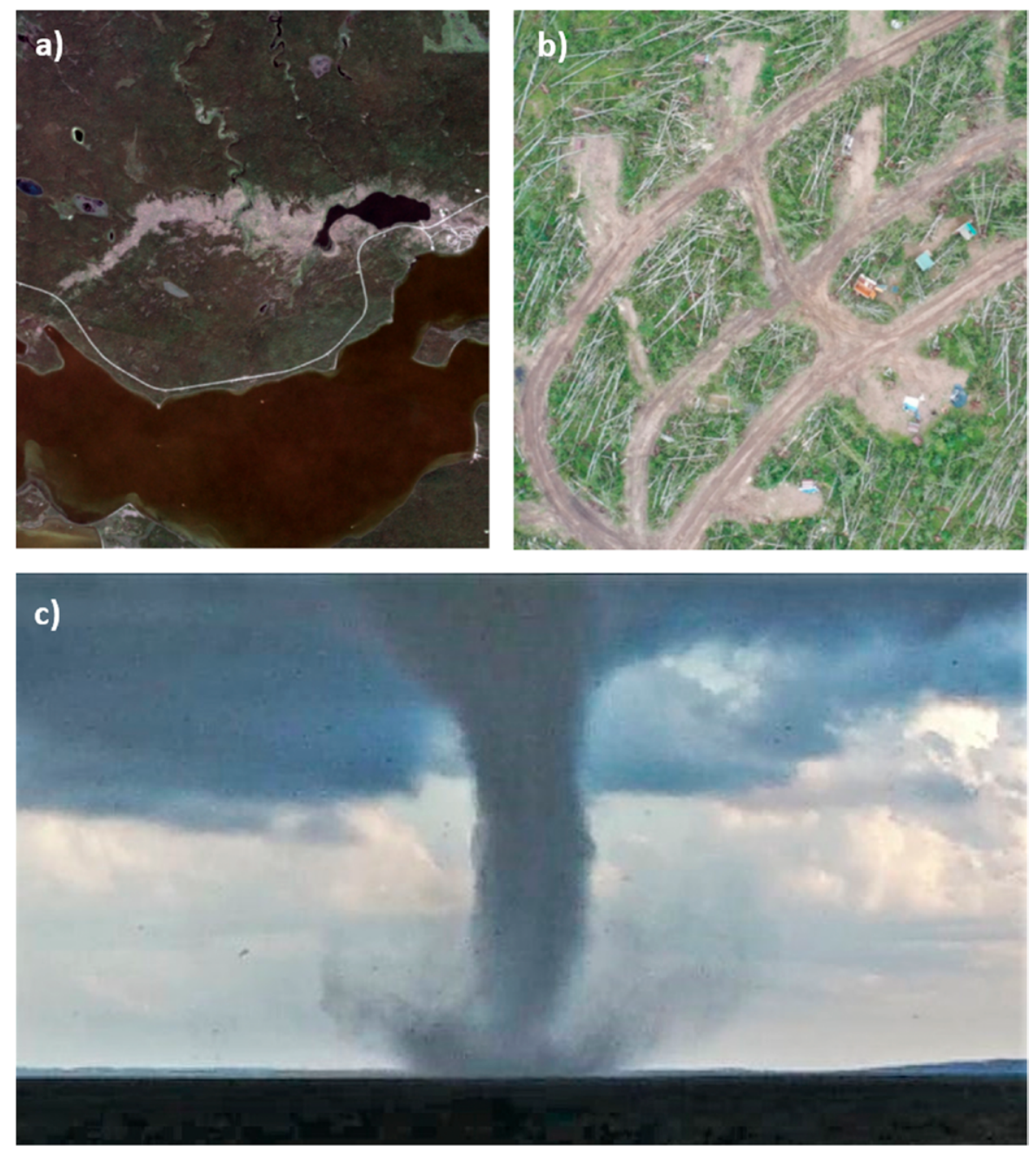

Fig. 9. Images from the 28/29 Jun 2019 tornado outbreak in Alberta/Saskatchewan: (a) a satellite view of the tornado damage through Meadow Lake Provincial Park beginning initially as a narrow path then turning right and becoming increasingly mixed with downburst damage as it crossed the lake; (b) the Murray Doell campground within Meadow Lake Provincial Park, with every tree uprooted or in some cases snapped; and (c) a video capture of the Cold Lake tornado (D. A. Moon/Facebook, used with permission). 
damage path lengths and maximum widths. A preliminary examination of the overall pattern of NTP-verified tornadoes across Canada is compared to observations and statistical modeling results.

Comparing damage intensities. Table 2 compares the tornado counts and percentages by F-/EF-scale rating for the 30YCA
Table 2. Comparison of damage intensity ratings (F/EF scale) for 3OYCA and NTPCA.

\begin{tabular}{|lccccccc|}
\hline & 0 & 1 & 2 & 3 & 4 & 5 & Total \\
30YCA tornadoes & 1,209 & 473 & 128 & 23 & 5 & 1 & 1,839 \\
30YCA (\%) & 65.7 & 25.7 & 7 & 1.3 & 0.3 & 0.1 & 100 \\
NTPCA tornadoes & 48 & 65 & 38 & 2 & 1 & 0 & 154 \\
NTPCA (\%) & 31.2 & 42.2 & 24.7 & 1.3 & 0.6 & 0 & 100 \\
\hline
\end{tabular}

and NTPCA datasets, while Fig. 10 shows the number of tornadoes per 30 years by F-/EF-scale value on a log-linear graph. Brooks and Doswell (2001) have shown that the F2-F4 slope on a log-linear graph can be used to assess the quality of a tornado database, in particular, the relative frequencies of tornadoes by F scale. Figure 10 shows the 30YCA dataset follows the F2-F4 slope fairly well. However, the slope line suggests that the number of F0 tornadoes is significantly underestimated, less so for F1 tornadoes.

The NTPCA dataset is not as well behaved. Though this is expected to improve as the sample size grows in the coming years, there appears to be significant under-estimation of EF0 tornadoes and significant over-estimation of EF2 tornadoes (less so for EF1). Given the many NTP tornadoes found in forests, where most tornadoes were rated EF1/2 but very few were rated EFO (given the limitations of remote sensing), this is an understandable bias.

In addition, a large number of tornadoes that make up the NTPCA dataset are from tornado outbreaks. When comparing outbreak events with nonoutbreak events, in both Canada (using the 30YCA dataset) and the United States (using the 1990-99 dataset), it is clear that the conditions that lead to outbreak events also lead to more intense storm damage and thus higher F-/EF-scale damage ratings (Fig. 11). So, the large number of EF2 tornadoes in the NTPCA dataset may be due to the fact that many of the NTPCA tornadoes occurred as part of large outbreaks. This is supported by Banik et al. (2012), who used a simulation-based approach to find that tornado outbreaks over large areas can have a substantially higher tornado hazard.

Some EF2 tornadoes in forests may instead warrant a rating of $\mathrm{EF} 3$, but this is difficult to establish with remote sensing alone, which is the case for many of the tornadoes detected via forest scars.

\section{Comparison of path length and maximum path width. The} 30YCA dataset has 1,839 tornado events, with 157 of those being significant tornadoes (F/EF2+). However, the number of events having path length and maximum path width data are far less, at 289 and 222 events, respectively, with the majority from Ontario. Each tornado event in the NTPCA dataset has length and maximum width data, though with even fewer

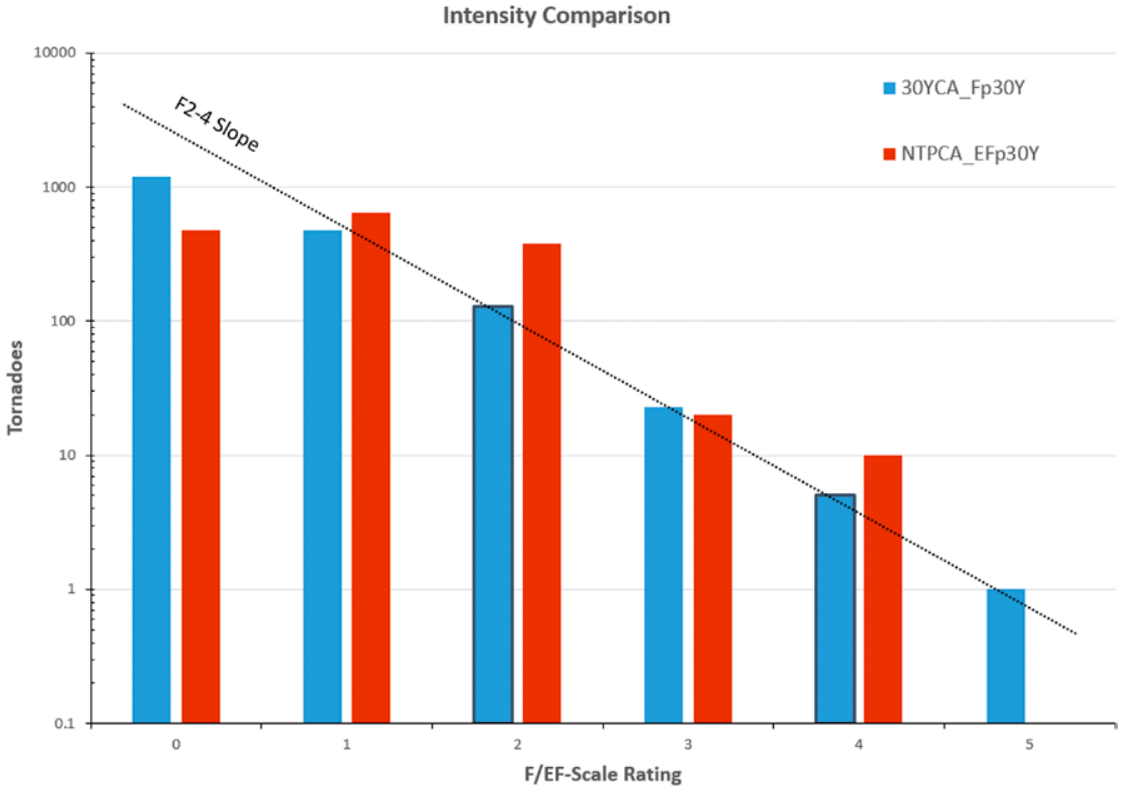

Fig. 10. Chart showing the number of tornadoes per 30 years by F-/EFscale value on a log-linear graph. Blue bars represent the 30 -yr dataset while red bars represent the 3-yr NTP dataset. Note that no EF5 tornadoes have been recorded to date by NTP. The dotted line represents the F2-F4 slope for 30YCA (F2 and F4 bars are also highlighted). 
events at 154 and the majority of events from Ontario and Quebec. Recognizing the representative limitations of both datasets, we set out to compare and contrast these spatial characteristics.

Considering significant tornadoes, the sample size gets lower-79 30YCA significant events with path length, 55 30YCA significant events with maximum path width, and 41 NTPCA significant events-but these events are included for comparison to obtain preliminary results.

Figure 12 a shows box-andwhisker diagrams for each of the path length datasets. The mean path lengths are similar, with $10.6 \mathrm{~km}$ for 30YCA and $10.3 \mathrm{~km}$ for NTPCA. In both cases, the mean path length for significant tornadoes is substantially longer

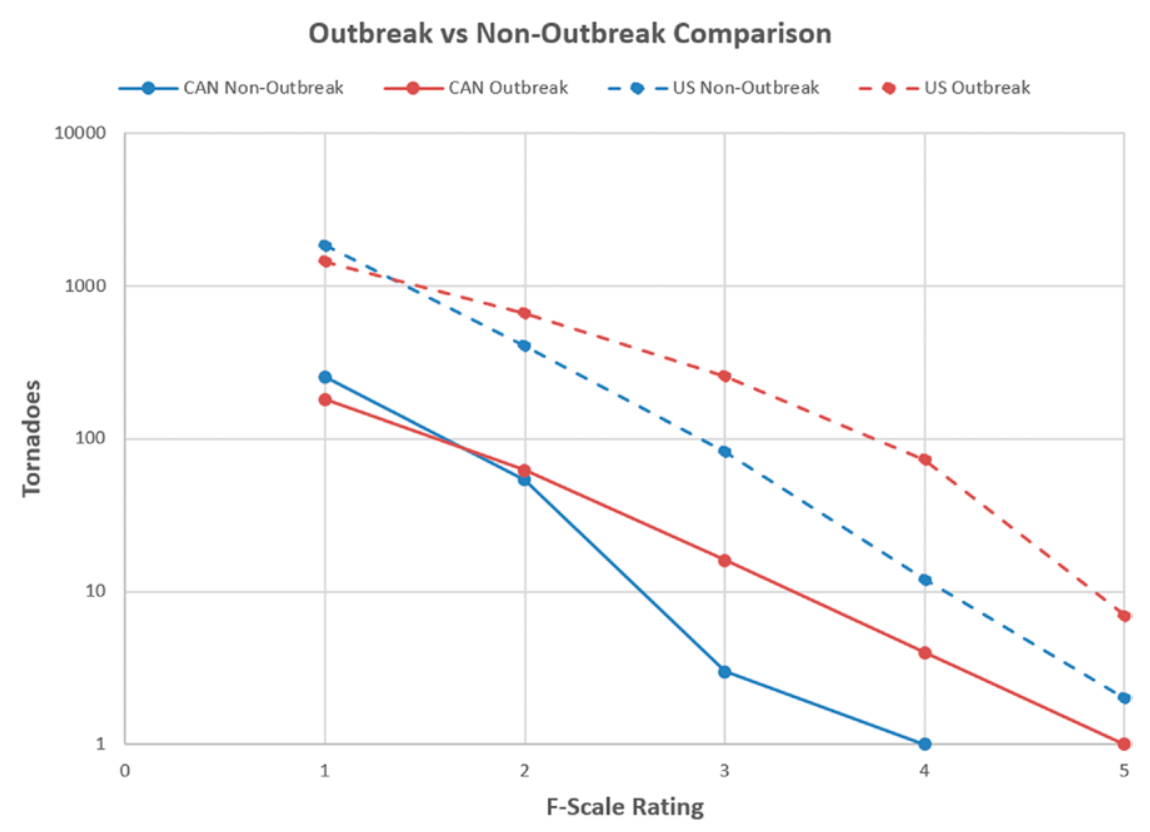

Fig. 11. Log-linear plot of Canadian (1980-2009, solid) and U.S. (1990-99, dashed) F1+ tornadoes for nonoutbreak days (blue) and outbreak days (red). Canadian outbreaks are defined here as at least two F1+ tornadoes on the same day, while U.S. outbreaks are defined as eight F1+ tornadoes on the same day. The sample sizes for the outbreak and nonoutbreak tornadoes is 312 and 263, respectively, for the 30YCA dataset, and 2,335 and 2,431 , respectively, for the U.S. dataset.

at 23.9 and $16.1 \mathrm{~km}$, respectively. A number of events having lengths of $70 \mathrm{~km}$ or greater are evident for the 30YCA datasets. The difference here with NTPCA datasets may be due to a greater ability on the part of the NTP, given the higher-resolution tools now available, to discriminate multiple nearby tornadoes rather than connect damage resulting in one longer path.

Box-and-whisker diagrams for each of the maximum path width datasets are shown in Fig. 12b. The mean width for NTPCA at $466 \mathrm{~m}$ is substantially greater than $249 \mathrm{~m}$ for 30YCA. For significant tornadoes, there is also a substantial difference with the mean for NTPCA at $760 \mathrm{~m}$ and the mean for 30YCA at $391 \mathrm{~m}$. This seems to be the result of underestimation for the 30YCA dataset. For example, there are 11 significant tornadoes in the 30YCA dataset with maximum path widths less than $100 \mathrm{~m}$, some even down to $20 \mathrm{~m}$ [unlikely for significant tornadoes, as shown by Brooks (2004)]. In contrast, for NTPCA the smallest width for significant tornadoes is $190 \mathrm{~m}$. The reasons for the underestimation are unclear, but the difference may be due to more thorough analysis on the part of NTP using high-resolution remote sensing tools.

In all cases, the results agree with Brooks (2004) in that tornado path lengths and widths generally increase with increasing damage intensity.

Preliminary comparison of NTP tornadoes and expected occurrence pattern. Figure 13 shows all of the NTP-documented tornadoes across the country with selected contours from the tornado frequency modeling of Cheng et al. (2013, discussed earlier) superimposed. Several points are notable. First, while the model extended the 0.1 tornadoes per $10,000 \mathrm{~km}^{2}$ per year contour well into northern parts of Alberta, Saskatchewan, Manitoba and northern Ontario, no tornadoes were recorded there by NTP (though one tornado was recorded in Northwest Territories close to the border with Alberta, well outside that contour). Most of this region is heavily forested so the detection of tornado scars should be no more difficult than in more southern regions.

Second, the model predicted a maximum in tornado frequency over southern Saskatchewan. Though 10 tornadoes were found to occur within that contour, it does not (yet) stand out in 

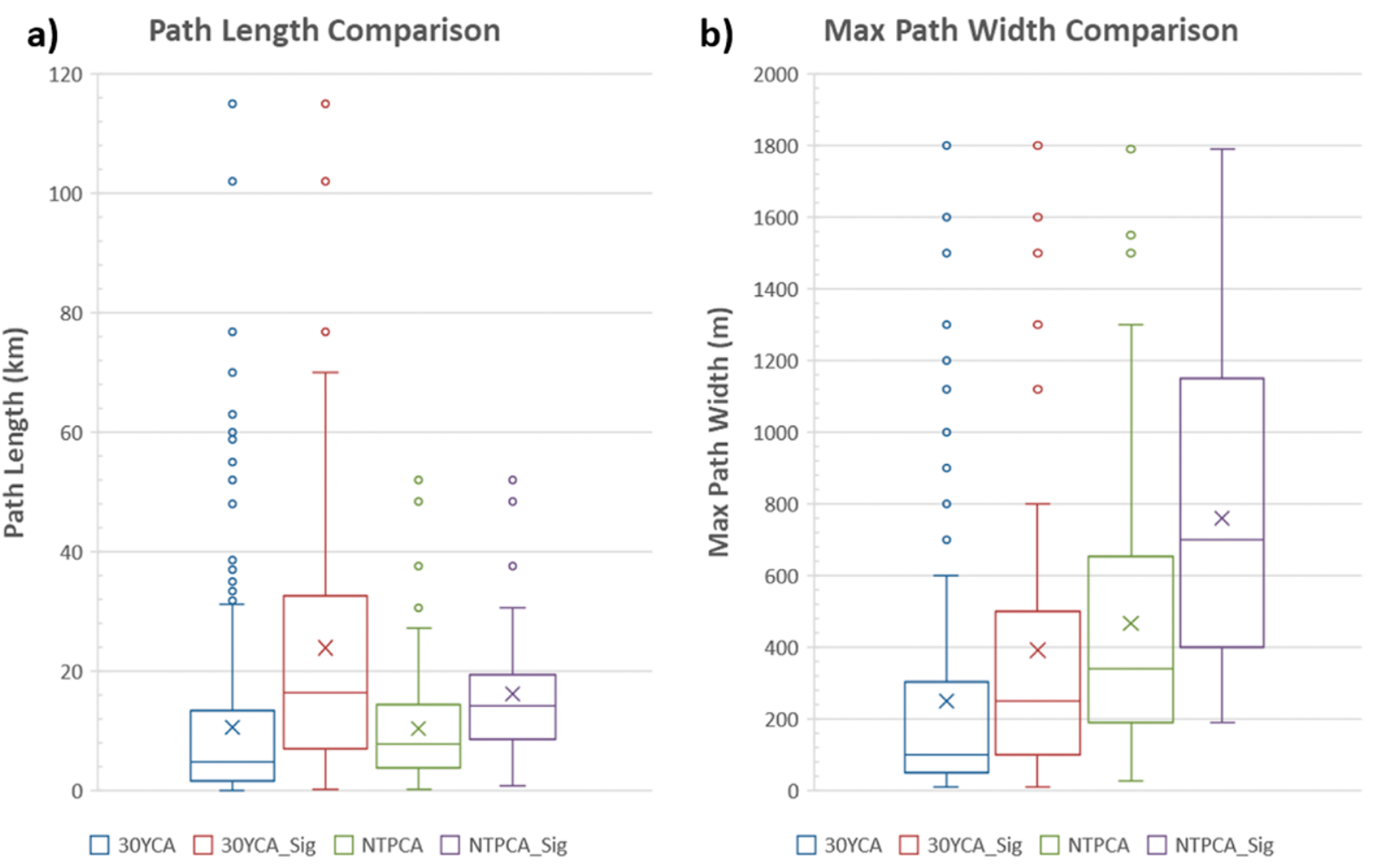

Fig. 12. Box-and-whisker plots for (a) path length comparison of 30-yr dataset with NTP dataset, for both all tornadoes and only F/EF2+, and (b) maximum path width comparison of 30-yr dataset with NTP dataset, for both all tornadoes and only F/EF2+. The horizontal line within the box represents the median while the $\times$ symbol represents the mean. Outliers are shown as circles.

the observations as an area having enhanced frequency nationally. The southwestern part of northern Ontario had more tornadoes over a similar area.

Finally, there is the strong maximum in observed tornado occurrence over southern Quebec. This mainly forested region north of the Montreal-Quebec City corridor is within the 0.1 tornadoes per $10,000 \mathrm{~km}^{2}$ per year contour, but the number of tornadoes recorded there by NTP far exceeds any other area of Canada. Of these tornadoes, 38 occurred during just three tornado outbreaks (see Fig. 7). The enhanced activity here is surprising given that the 1980-2009 average annual tornado frequency for all of Quebec is only 4.7. It is possible that this is part of a longer-term trend. Gensini and Brooks (2018) have noted that the traditional "Tornado Alley" in the central United States is beginning to shift eastward, with tornado environments shifting northeastward during the June-August period (Fig. 6c). However, it would take many more years of observations in Canada to confirm if a similar shift is also underway here. It is more likely that the recent Quebec maximum is solely a product of year-to-year variation.

The reader is reminded that this is a preliminary comparison-as more data are collected, some of these differences may be reduced in magnitude.

\section{Conclusions}

The mission of the Northern Tornadoes Project is to determine Canada's true tornado climatology. Campaigns during the 2017, 2018, and 2019 tornado seasons investigated and classified a total of 391 events, including 89 tornadoes that otherwise would not have been identified (considerably more than the 1980-2009 national average frequency of 61.3 tornadoes per year). NTP-discovered tornadoes increased annual tornado totals by a significant percentage $(\sim 78 \%-283 \%)$. Event data quality was enhanced by NTP for another 65 tornadoes.

Comparing the NTP tornado dataset with that from 1980 to 2009 suggests that NTP is more accurately assessing damage path lengths and maximum widths, though it will take 


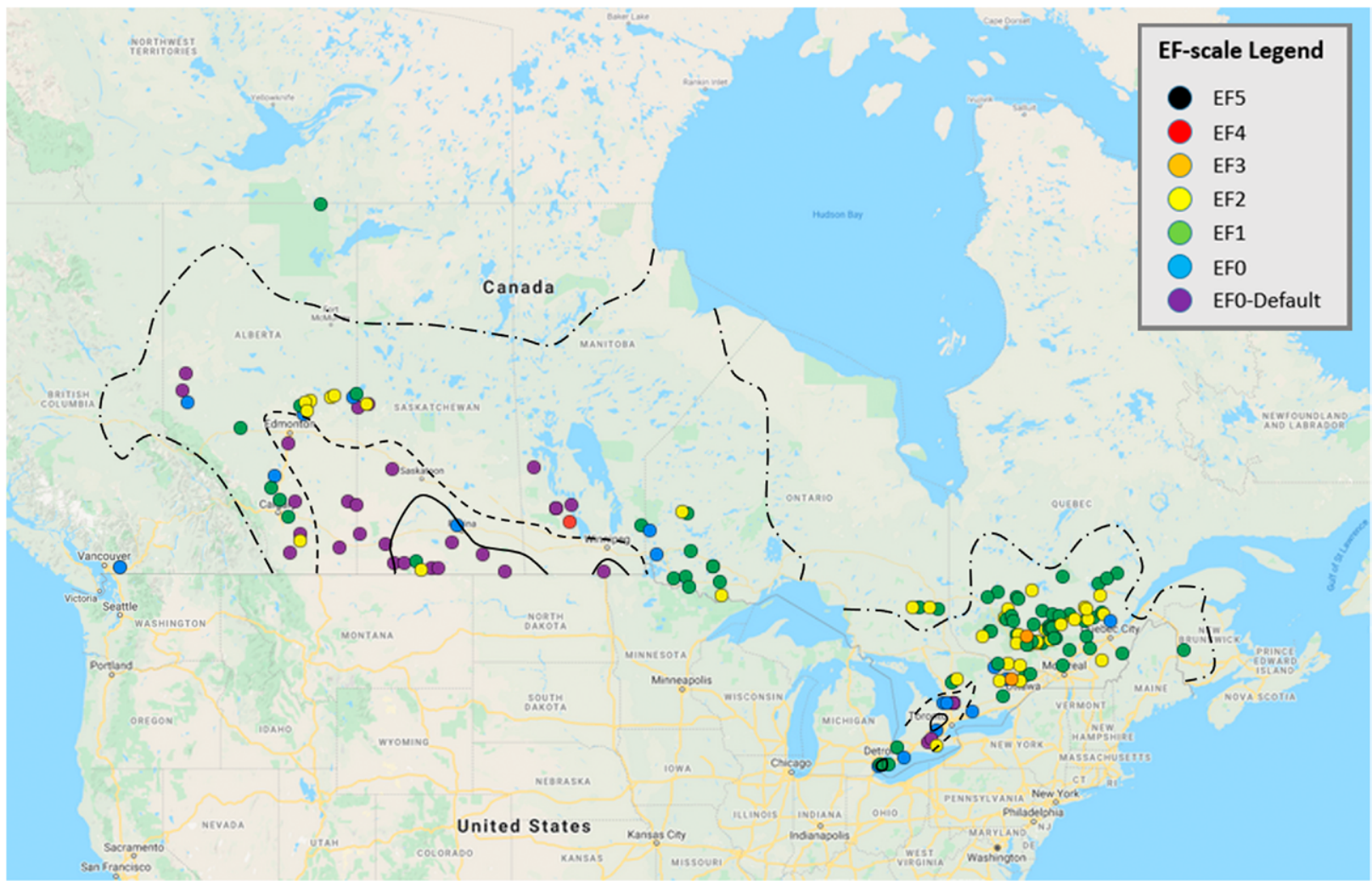

Fig. 13. All 2017-19 tornadoes by EF scale. Superimposed are smoothed contours of average annual tornado frequency in tornadoes per $10,000 \mathrm{~km}^{2}$ per year from Cheng et al. (2013): dash-dotted = 0.1, dashed $=1.0$, and solid $=2.0$. Map data $\odot 2020$ Google.

a number of additional years of data to determine how well intensity is being characterized. Efforts are underway to improve tornado detection and data quality further by adopting new technologies and investigating novel techniques.

Acknowledgments. This research was funded by ImpactWX and the University of Western Ontario. Thanks to the staff and management at ECCC offices across the country, plus retired ECCC staff Geoff Coulson, Patrick McCarthy, René Héroux, Arnold Ashton, and Paul Joe. John Hanesiak at the University of Manitoba, Jennifer Spinney at York University, and Chris Scott and Dayna Vettese at The Weather Network were instrumental in the development of NTP partnerships with those institutions. Harold Brooks (NSSL) provided the 1990s U.S. tornado data and useful insights for analysis of the outbreak vs nonoutbreak tornado comparison. The authors would also like to thank two anonymous reviewers for comments and suggestions that improved the manuscript.

Data availability statement. The data and documentation described in this paper are considered to be "open access" and are available via the NTP website: uwo.ca/ntp.

\section{Appendix: Description of the NTP forest box method}

The Canadian EF scale includes a tree DI that requires the percentage of trees down along a portion of a tornado path as input. A method was developed by NTP to estimate the percentage of trees snapped or uprooted over a sampling area in order to consistently employ the tree DI. The following steps are required, as illustrated in Fig. A1.

- Step 1-Create a contour around the detected EF0 or higher damage along the tornado damage path and find the damage centerline (center of the damage along the path) and the tornado centerline (confluence line along the damage path). 
- Step 2-Using a line perpendicular to the damage centerline, find the maximum path width.

- Step 3-Create a sampling box that is $50 \%$ of the maximum path width on all sides.

- Step 4-Use the sampling box at various locations along the path to estimate the percentage of trees uprooted/snapped and determine the degree of damage (DOD), particularly in the area of worst damage (which may not be at the location of maximum width).

- Step 5-Estimate the maximum wind speed based on the DOD for each box.

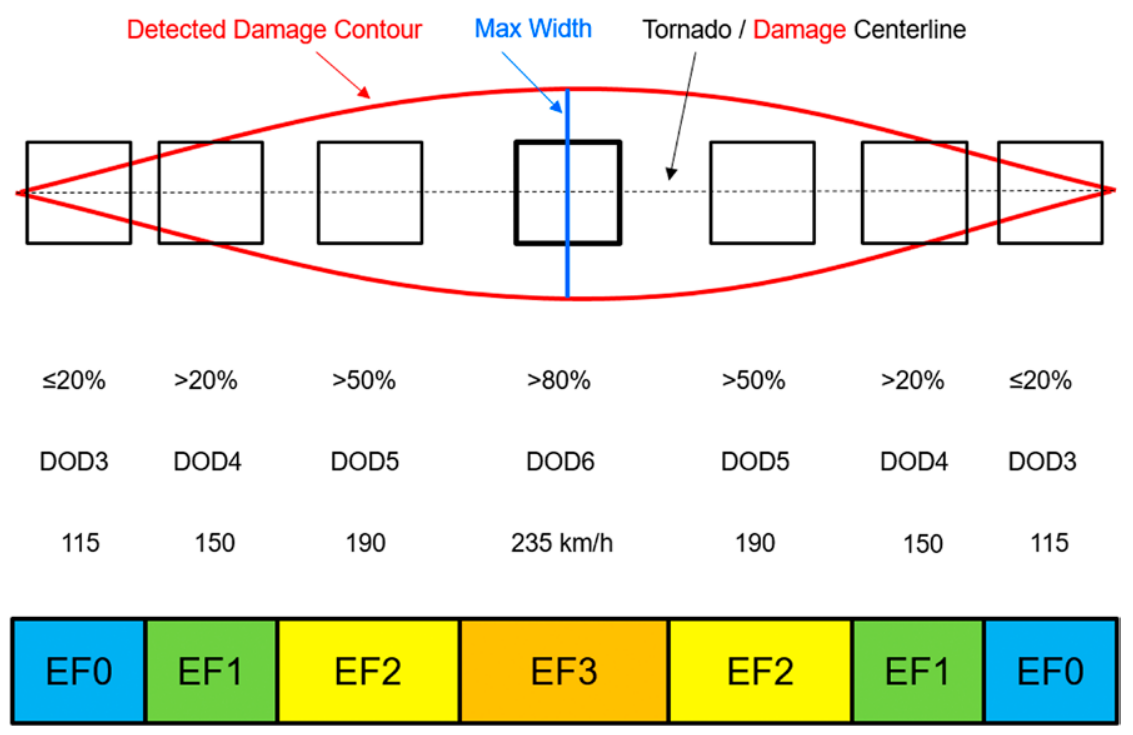

Fig. A1. An idealized example of the use of the "forest box method" to assess the forest damage intensity associated with an EF3 tornado having a straight path. With a straight path, the tornado centerline and the damage centerline are essentially the same. However, this is typically not the case for curved paths or paths with fast-moving tornadoes.

- Step 6-Determine the EF-scale rating based on the estimated maximum wind speed for each box.

- Step 7-Use the maximum EF-scale rating along the track to assign an EF-scale rating to the tornado.

Note that the sampling box

- must be aligned with the tornado centerline at the location being sampled but can be moved across the tornado centerline to the location best representing the damage as long as the tornado centerline goes through the sampling box or is along its edge,

- must be no less than $100 \mathrm{~m}$ per side, and

- must have at least 50\% treed area within the box when sampling.

NTP has tested the forest box method against numerous cases with aerial data and found that it provides a consistent approach that matches results from other damage indicators. If samples are taken at representative locations along the damage path, a 1D representation of the EF ratings along the tornado track can be generated. Other benefits are that the sampling box scales with tornado path width and that its application is fairly simple and fast. 
Alberta Public Safety Services, 1990: Tornado-A report: Edmonton and Strathcona County, July 31st 1987. Government of Alberta Rep., 187 pp.

ASCE, 1994: Glossary of the Mapping Sciences. ASCE Publications, 581 pp.

Baker, C. J., and M. Sterling, 2018: A conceptual model for wind and debris impact loading of structures due to tornadoes. J. Wind Eng. Ind. Aerodyn., 175, 283-291, https://doi.org/10.1016/j.jweia.2017.11.029.

Banik, S. S., H. P. Hong, and G. A. Kopp, 2012: Assessment of the wind hazards due to tornado outbreaks in southern Ontario. J. Wind Eng. Ind. Aerodyn., 107-108, 28-35, https://doi.org/10.1016/j.jweia.2012.03.003.

Brooks, H. E., 2004: On the relationship of tornado path length and width to intensity. Wea. Forecasting, 19, 310-319, https://doi.org/10.1175/1520-0434 (2004)019<0310:0TROTP>2.0.C0;2.

— of tornadoes by damage classification. Atmos. Res., 56, 191-201, https://doi. org/10.1016/S0169-8095(00)00098-3.

Charlton, R. B., B. M. Kachman, and L. Wojtiw, 1998: The Edmonton tornado and hailstorm: A decade of research. CMOS Bull., 26, 1-56.

Cheng, V. Y. S., G. B. Arhonditsis, D. M. L. Sills, H. Auld, M. W. Shephard, W. A. Gough, and J. Klaassen, 2013: Probability of tornado occurrence across Canada. J. Climate, 26, 9415-9428, https://doi.org/10.1175/JCLI-D-13-00093.1.

Dutta, A., and A. Zisserman, 2019: The VIA Annotation Software for images, audio and video. Proc. 27th Int. Conf. on Multimedia, Nice, France, Association for Computing Machinery, https://doi.org/10.1145/3343031.3350535.

Etkin, D., S. E. Brun, A. Shabbar, and P. Joe, 2001: Tornado climatology of Canada revisited: Tornado activity during different phases of ENSO. Int. J. Climatol., 21, 915-938, https://doi.org/10.1002/joc.654.

Gensini, V. A., and H. E. Brooks, 2018: Spatial trends in United States tornado frequency. npj Climate Atmos. Sci., 1, 38, https://doi.org/10.1038/s41612-018 $-0048-2$.

Grazulis, T. P., 2000: Canadian Killer Tornadoes. The Tornado Project, 19 pp.

Haan, F. L., V. K. Balaramudu, and P. P. Sarkar, 2010: Tornado-induced wind loads on a low-rise building. J. Struct. Eng., 136, 106-116, https://doi.org/10.1061/ (ASCE)ST.1943-541X.0000093.

He, K., G. Gkioxari, P. Dollár, and R. B. Girshick, 2020: Mask R-CNN. IEEE Trans. Pattern Anal. Mach. Intell., 42, 386-397, https://doi.org/10.1109/TPAMI.2018.2844175.

Hu, H., Z. Yang, P. Sarkar, and F. Haan, 2011: Characterization of the wind loads and flow fields around a gable-roof building model in tornado-like winds. Exp. Fluids, 51, 835-851, https://doi.org/10.1007/s00348-011-1102-6.

IBC, 2018: Ottawa-Gatineau tornadoes cause $\$ 295$ million in insured damage. Accessed 16 June 2020, www.ibc.ca/on/resources/media-centre/mediareleases/ottawa-gatineau-tornadoes-cause-295-million-in-insured-damage.

Jedlovec, G. J., U. Nair, and S. L. Haines, 2006: Detection of storm damage tracks with EOS data. Wea. Forecasting, 21, 249-267, https://doi.org/10.1175/WAF923.1.

Kopp, G. A., and C.-H. Wu, 2017: A framework for the aerodynamics of low-rise buildings in tornadoes: Can boundary layer wind tunnels give us everything we need? Proc. 13th Americas Conf. on Wind Engineering, Gainesville, FL, American Association for Wind Engineering.

_ - E. Hong, E. Gravanski, D. Stedman, and D. Sills, 2017: Assessment of wind speeds based on damage observations from the Angus (Ontario) tornado of 17 June 2014. Can. J. Civ. Eng., 44, 37-47, https://doi.org/10.1139/cjce-2016-0232.

Kosiba, K. A., and J. Wurman, 2013: The three-dimensional structure and evolution of a tornado boundary layer. Wea. Forecasting, 28, 1552-1561, https:// doi.org/10.1175/WAF-D-13-00070.1.

Lombardo, F. T., D. B. Roueche, and D. O. Prevatt, 2015: Comparison of two methods of near-surface wind speed estimation in the 22 May, 2011 Joplin, Missouri tornado. J. Wind Eng. Ind. Aerodyn., 138, 87-97, https://doi.org/10.1016/j.jweia.2014.12.007.

Lowe, A. B., and G. A. McKay, 1962: The Tornadoes of Western Canada. Government of Canada, 42 pp.

Markowski, P., and Y. Richardson, 2010: Mesoscale Meteorology in Midlatitudes. Wiley-Blackwell, $430 \mathrm{pp}$.

Mehta, K., 2013: Development of the EF-scale for tornado intensity. J. Disaster Res., 8, 1034-1041, https://doi.org/10.20965/jdr.2013.p1034.
Mikuš, P., and N. S. Mahović, 2013: Satellite-based overshooting top detection methods and an analysis of correlated weather conditions. Atmos. Res., 123, 268-280, https://doi.org/10.1016/j.atmosres.2012.09.001.

Mohammadi, M. E., D. P. Watson, and R. L. Wood, 2019: Deep learning-based damage detection from aerial SfM point clouds. Drones, 3, 68, https://doi. org/10.3390/drones3030068.

Molthan, A. L., J. R. Bell, T. A. Cole, and J. E. Burks, 2014: Satellite-based identification of tornado damage tracks from the 27 April 2011 severe weather outbreak. J. Oper. Meteor., 2, 191-208, http://dx.doi.org/10.15191/nwajom.2014.0216.

Newark, M. J., 1984: Canadian tornadoes, 1950-1979. Atmos.-Ocean, 22, 343353, https://doi.org/10.1080/07055900.1984.9649203.

NOAA, 2018: Storm data preparation. National Weather Service Instruction 101605, 110 pp.

Ramseyer, C., R. Floyd, L. Holliday, and S. Roswurm, 2014: Influence of lateral load bracing systems on damage and survivability of residential structures impacted by the Moore, Oklahoma, tornado of May 20, 2013. Proc. Structures Congress 2014, Boston, MA, ASCE, 1484-1507, https://doi.org/10.1061/9780784413357.131.

Refan, M., and H. Hangan, 2016: Characterization of tornado-like flow fields in a new model scale wind testing chamber. J. Wind Eng. Ind. Aerodyn., 151, 107-121, https://doi.org/10.1016/j.jweia.2016.02.002.

$\longrightarrow$, and 2018: Near surface experimental exploration of tornado vortices. J. Wind Eng. Ind. Aerodyn., 175, 120-135, https://doi.org/10.1016/j.jweia .2018.01.042.

Sayn-Wittgenstein, L., and J. M. Wightman, 1975: Landsat application in Canadian forestry. Proc. 10th Int. Symp. on Remote Sensing of Environment, Ann Arbor, MI, Environmental Research Institute of Michigan, 1209-1218.

Schenkman, A. D., and M. Xue, 2016: Bow-echo mesovortices: A review. Atmos. Res., 170, 1-13, https://doi.org/10.1016/j.atmosres.2015.11.003.

Shikhov, A., and A. Chernokulsky, 2018: A satellite-derived climatology of unreported tornadoes in forested regions of northeast Europe. Remote Sens. Environ., 204, 553-567, https://doi.org/10.1016/j.rse.2017.10.002.

Sills, D. M. L., and P. I. Joe, 2019: From pioneers to practitioners: A short history of severe thunderstorm research and forecasting in Canada. Atmos.-Ocean, 57, 249-261, https://doi.org/10.1080/07055900.2019.1673145.

_ V. Cheng, P. J. McCarthy, B. Rousseau, J. Waller, L. Elliott, J. Klaassen, and H. Auld, 2012: Using tornado, lightning and population data to identify tornado prone areas in Canada. 26th Conf. on Severe Local Storms, Nashville, TN, Amer. Meteor. Soc., 59, https://ams.confex.com/ams/26SLS/webprogram/Paper211359.html.

_ P. J. McCarthy, and G. A. Kopp, 2014: Implementation and application of the EFscale in Canada. 27th Conf. on Severe Local Storms, Madison, WI, Amer. Meteor. Soc., 16B.6, https://ams.confex.com/ams/27SLS/webprogram/Paper254999.html.

Sudha, R., Y.Tamura, and M. Matsui, 2012: Use of post-storm images for automated tornado-borne debris path identification using texture-wavelet analysis. J. Wind Eng. Ind. Aerodyn., 107-108, 202-213, https://doi.org/10.1016/j.jweia.2012.04.016.

van de Lindt, J. W., S. Pei, T. Dao, A. Graettinger, D. O. Prevatt, R. Gupta, and W. Coulbourne, 2013: Dual-objective-based tornado design philosophy.J. Struct. Eng., 139, 251-263, https://doi.org/10.1061/(ASCE)ST.1943-541X.0000622.

Van Den Broeke, M. S., and S. T. Jauernic, 2014: Spatial and temporal characteristics of polarimetric tornadic debris signatures. J. Appl. Meteor. Climatol., 53, 2217-2231, https://doi.org/10.1175/JAMC-D-14-0094.1.

Wagner, M., R. K. Doe, A. Johnson, Z. Chen, J. Das, and R. S. Cerveny, 2019: Unpiloted aerial systems (UASs) application for tornado damage surveys: Benefits and procedures. Bull. Amer. Meteor. Soc., 100, 2405-2409, https:// doi.org/10.1175/BAMS-D-19-0124.1.

Wakimoto, R. M., and J.W.Wilson, 1989: Non-supercell tornadoes. Mon. Wea. Rev., 117, 1113-1140, https://doi.org/10.1175/1520-0493(1989)117<1113:NST>2.0.C0;2.

Womble, J. A., R. L. Wood, and M. E. Mohammadi, 2018: Multi-scale remote sensing of tornado effects. Front. Built Environ., 4, 22, https://doi.org/10.3389/fbuil.2018.00066.

Yuan, M., M. Dickens-Micozzi, and M. A. Magsig, 2002: Analysis of tornado damage tracks from the 3 May tornado outbreak using multispectral satellite imagery. Wea. Forecasting, 17, 382-398, https://doi.org/10.1175/15200434(2002)017<0382:AOTDTF>2.0.CO;2. 